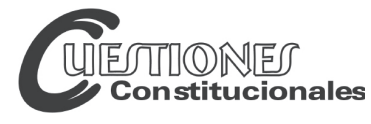

Revista Mexicana de Derecho Constitucional

Núm. 27, julio-diciembre 2012

\title{
LA TRASCENDENCIA DEL CONSTITUCIONALISMO SOCIAL EN AMÉRICA LATINA (CASO MÉXICO)
}

\author{
THE SIGNIFICANCE OF THE SOCIAL CONSTITUTIONALISM \\ IN LATIN AMERICA (CASE MEXICO)
}

\begin{abstract}
RESUMEN: América Latina se hermana a través de su devenir histórico, por un lado, por su legado autóctono proveniente de las culturas mesoamericanas y de los andes. Años más tarde con la presencia europea se gesta un proceso de aculturación que se identificó como la época novohispana, que se sustentó en la explotación y expoliación tanto de los recursos naturales como de la población autóctona y mestiza, generando amplios sectores sociales que se empobrecieron de manera dramática, hasta llegar a las guerras de independencia durante el siglo XIX. Sin embargo, las asimetrías siguieron y hubo necesidad de movimientos reivindicatorios mediante revoluciones, al respecto cabe citar, la Revolución mexicana de 1910-1917, suceso histórico que sumó aproximadamente de uno a dos millones de muertos, por lo cual, representó un parteaguas en la historia de América Latina y del mundo.
\end{abstract}

Palabras clave: constitucionalismo social, pobreza, desigualdad, justicia social, empleo, vivienda, educación pública y gratuita, seguridad social, planeación estatal, intervención estatal, políticas económicas neoliberales.

\section{Rafael SÁNCHEZ VÁZQUEZ}

ABSTRACT: Latin American share its historical evolution, on one hand, the indigenous legacy from Mesoamerican and Andean cultures, years after, with the European presence takes place a process of acculturation that is known as the era of new Spain, supported with the exploitation and spoliation not only of natural resources but also of indigenous and mestizo population generating broad social sectors impoverished dramatically, up to the independence wars in the 19th century. However, asymmetries continued what led to claim movements that ended in revolutions, At this point we want to mention the 1910-1917 mexican Revolution, historical event that left behind approximately one to two million dead, therefore, is considered as a turning point in the Latin-American and world history.

Descriptors: social constitutionalism, poverty, inequality, social justice, employment, housing, public and free education, social security, State planning, State intervention, neoliberal economic policies.

* Doctor en derecho por la UNAM; profesor investigador de la Facultad de Derecho y C. S. de la BUAP. 
El Estado social en el aspecto económico se contrapone con la tendencia neoliberal en boga, pues este, se inspira en la influencia de mas leyes del mercado y de la competencia, por otra parte, está a revisión en la política y el derecho, en las que se habla de crisis del Estado social, ya que se transita del estado de bienestar al Estado de malestar, que el Estado para ser eficiente debe ser modesto y que debe luchar contra el Estado megalómano. ${ }^{1}$

El constitucionalismo social actualmente sufre verdaderos embates en contra. En México también, por ello, hay que luchar por la justicia social el aspecto más importante de nuestra Constitución Mexicana. ${ }^{2}$

La moral pública en México se encuentra enferma, es necesario un cambio de mentalidad, por el bien del país. Empero son vicios muy antiguos y arraigados en nuestra sociedad. Los conoció y sufrió la sociedad colonial durante casi tres siglos. Los mismos perduraron durante los siglos XIX, XX y sigue en los primeros nueve años del siglo XXI. Ahora bien, cuando los servidores públicos son incompetentes, irresponsables, no comprometidos con su labor o corruptos, una combinación de algunos de estos aspectos, y que giran en torno al poder, dinero, corrupción, impunidad y mentiras. Así pues, dichas actitudes ponen en riesgo las mejores instituciones, ya que se encaminan ineluctablemente al fracaso. ${ }^{3}$

El verdadero mal del siglo XX que fenece, es la corrupción generalizada que preside a la cultura mundial. Así pues, la corrupción no sólo la identificamos en la esfera pública sino también la que se desarrolla en el ámbito privado. Por ello debe entenderse que la estrategia para combatir a la corrupción debe abarcar a todos los sectores sociales, a los sujetos de todas las edades. ${ }^{4}$

1 Fix-Zamudio, Héctor y Valencia Carmona Salvador, Derecho constitucional mexicano y comparado, México, Porrúa, 1999, pp. 534 y 535.

2 Cfr. Carpizo, Jorge, "México: hacia una nueva Constitución", Estudios de teoría del Estado y derecho constitucional en honor de Pablo Lucas Verdú, México, UNAM, Instituto de Investigaciones Jurídicas, México, 2000, t. II, pp. 892 y 893.

3 Cfr. Carpizo, Jorge, Moral pública y libertad de expresión, México, Jus, 2009, pp. 11,23 y ss.

4 V. Castro, Juventino, La mutación estructural del derecho en México, México, Porrúa, 1998, pp. 60-63. 


\section{PRESENTACIÓN}

Los latinoamericanos sumamos una población aproximada a los 603 millones de habitantes, con un alto índice de pobres que rebasa a los 250 millones, ocupamos una extensión territorial de 21, 637, $049 \mathrm{Km} 2$, que va del norte de la República Mexicana hasta la Patagonia. Lamentablemente, las desigualdades económicas y sociales en América Latina, son crónicas, de poco más de cuatro siglos.

Tenemos un pasado histórico - autóctono- Las culturas que se desarrollaron tanto en Mesoamérica ${ }^{5}$ (olmecas, toltecas, cholultecas, zapotecas, mayas, aztecas, otomíes, etcétera) como en la Cordillera Andina (Incas), el maíz forma parte de su cultura alimentaria. Además, su organización social y política se instrumentó como un régimen teocrático militar, en una población aproximada a más de 30 millones de habitantes. ${ }^{6}$

Por otra parte, cabe resaltar, que durante muchos años se difundió la idea de que las culturas que se desarrollaron en Mesoamérica, no alcanzaron a rebasar la edad paleolítica, por no decir, que se quedaron en el umbral de la barbarie. Empero, los estudios más recientes han descubierto los avances científicos y técnicos que lograron las culturas prehispánicas, tanto en la medicina, botánica, zoología, ingeniería, arquitectura, astronomía, derecho y educación. Consecuentemente, nos permite reflexionar en paradigmas diferentes de pensar y hacer la generación del conocimiento. En tal virtud, nos conlleva a meditar acerca de la complejidad del conocimiento de las sociedades humanas que se han generado en lugares y épocas diferentes, sin dejar de existir en ocasiones ciertos paralelismos sociales y culturales. ${ }^{7}$

El 17 de abril de 1492, en Santa Fe de la Vega de Granada, los Reyes Católicos y Cristóbal Colón lograron ponerse de acuerdo en los términos y condiciones mediante los cuales éste último llevaría a cabo su empresa náutica, constando dicho acuerdo en el documento conocido como las capitulaciones de Santa Fe, y por lo tanto, se otorgan a Colón varios títulos:

5 Sánchez Vázquez, Rafael, Origen y desarrollo de la educación y el derecho en la época prehispánica, Puebla, Instituto de Investigaciones Jurídico Políticas de la Facultad de Derecho y Ciencias Sociales de la Benemérita Universidad Autónoma de Puebla, pp. $43,44,53$ y 54 .

6 Cfr. http://www.monografias.com/trabajos81/colonizacion-america-y-sus-consecuncias/colonizacion-america-y-sus-consecuencias2.shtml. Fecha de consulta: 4 de febrero de 2012.

7 Sánchez Vázquez, Rafael, op. cit., p. 415. 
almirante, virrey, gobernador general y demás prebendas. Además, se estableció que las tierras que encontrase en su camino a la India quedarían incorporadas a la Corona de Castilla. ${ }^{8}$

Sin embargo, sabemos que el 12 de octubre de 1492, Colón y su gente se toparon con un continente, ignoto para los europeos, y con ello se inició la penetración castellana primero y europea en general después, a nuestro continente. ${ }^{9}$

Así pues, con la presencia europea se gesta un proceso de aculturación que se identificó como la época novohispana. A partir de ese momento, Mesoamérica, con la llegada de los europeos, se le identifica como el nuevo mundo (el continente americano, en memoria de Américo Vespucio), desarrolla diferentes perspectivas del quehacer científico, tecnológico y cultural. Además, la lengua que se establece como vínculo de comunicación es en términos generales el castellano o español, y en un menor porcentaje, el portugués que se difunde en el territorio que ocupa Brasil. Ahora bien, los españoles legitiman su presencia al imponer la religión católica, a través de la evangelización mediante las encomiendas, así como su organización social y económica, eminentemente feudal, con absoluta dependencia con la corona española. Dicha dominación se conoce como época colonial con una duración de aproximadamente 300 años, la cual se sustentó en la explotación y expoliación, tanto de los recursos naturales como de la población autóctona y mestiza, generando amplios sectores sociales que se empobrecieron de manera dramática, hasta llegar a las guerras de independencia durante el siglo XIX.

Por otra parte, es importante resaltar la influencia del pensamiento social de los pensadores mexicanos del siglo XIX, entre otros, cabe hacer mención de: Mariano Otero, ${ }^{10}$ Ponciano Arriaga, Ignacio Ramírez “el nigromante", así como de los constituyentes de 1917.

8 Soberanes Fernández, José Luis, Historia del sistema jurídico mexicano, México, UNAM, Instituto de Investigaciones Jurídicas, 1990, p. 31.

9 Ibidem, p. 32.

10 De la mejora material depende también la realización de un orden social fundado sobre la libertad y la justicia. El establecimiento de un orden social equitativo y justo en el que la libertad sustituya un día completamente a la servidumbre, la igualdad a los privilegios, y la voluntad nacional a la fuerza bruta, depende también de la realización de las condiciones. Sencilla expresión del problema social. Las leyes se deben dirigir a garantizar a cada individuo, con el menor sacrificio posible, la satisfacción de todas sus facultades de hombre, y la organización de los poderes públicos no tienen otro objeto que el de establecer el poder más propio para expedir, conservar y ejecutar esas leyes 
Sin embargo, las desigualdades siguieron y hubo necesidad de movimientos reivindicatorios mediante revoluciones, al respecto cabe citar, la Revolución mexicana de 1910-1917, suceso histórico que sumó aproximadamente de uno a dos millones de muertos, por lo cual, representó un parteaguas en la historia de América Latina y del mundo. Experiencia amarga que llevó al pueblo mexicano a través de sus representantes políticos a conciliar intereses mediante una constitución paradigmática como lo fue la Constitución de 1917. En dicha carta magna, se trata de aminorar las desproporcionalidades: económicas, sociales, educativas, políticas, etcétera, mediante normas jurídicas constitucionales de Corte Social. A este respecto, cabe citar los siguientes artículos Constitucionales: 3o., 4o., 5o., 25, 26, 27, 28 y 123.

A mediados de la década de los setenta en Latinoamérica, - se inicia un proceso permanente y continuo de crisis financiera que trata de corregirsecon la imposición y aplicación de las políticas económicas neoliberales a partir de la década de los ochenta y que lamentablemente han perdurado con más énfasis en los últimos años.

Consecuentemente, aún percibimos en el entorno que rodea a Latinoamérica y a los latinoamericanos, las grandes desigualdades: económicas, sociales, educativas y políticas. Es decir, por una parte, existen concentraciones de la riqueza inimaginables, que pertenecen a unos cuantos, y por la otra, la presencia de amplios sectores sociales que viven en la miseria extrema. De ahí, el cuestionamiento permanente y continuo a las instituciones jurídicas, y sobre todo, la ruptura epistemológica en torno al concepto de la justicia, cuando ésta, generalmente, legitima el statu quo de las desigualdades.

Lamentablemente tanto para México como para otros países, se impusieron las políticas económicas neoliberales, desde 1982 a la fecha.

tutelares de los derechos humanos y de las relaciones sociales. Estos son los fines, y lo demás no es más que la ciencia de los medios que alcanza su realización. Necesidad de que las garantías individuales se funden sobre los progresos positivos o materiales. Otero, Mariano, Ensayo sobre el verdadero estado de la cuestión social y política que se agita en la República Mexicana, México, Impreso por Ignacio Cumplido, 1842, pp. 82 y 83.

Véase Sánchez Vázquez, Rafael, "La impronta de Don Mariano Otero en el Acta de Reformas de 1847", Actualidad de la Defensa de la Constitución de la Nación. Memoria del Coloquio Internacional en la Celebración del Acta de Reformas Constitucionales de 1847, origen Federal del Juicio de Amparo Mexicano, México, UNAM-Suprema Corte de Justicia de la Nación, 1997, p. 330. 
Ahora bien, teniendo en cuenta a lo antes mencionado, enseguida se hace referencia del problema central que es objeto de estudio de la presente investigación con su respectiva hipótesis de trabajo:

\section{Problema objeto de la investigación}

¿En qué forma las asimetrías socio-económicas, educativas, políticas e ideológicas influyeron en el surgimiento y desarrollo de escenarios acompañados de conflictos sociales armados? Por ejemplo, la revolución mexicana de 1910. Por una parte, y por la otra, ¿En qué forma las políticas neoliberales impuestas a México, a partir de la década de los ochenta — del siglo $\mathrm{XX}$ - hasta nuestros días han obstaculizado la observancia, el desarrollo y fortalecimiento de las normas constitucionales — de carácter social— que esquematizan al constitucionalismo social, ya que éstas, se establecieron como alternativas racionales para aminorar las asimetrías en la distribución del ingreso y de la riqueza, paradigma que caracteriza a nuestros pueblos desde la época de nuestra independencia?

\section{Hipótesis de trabajo}

A mayor presencia y observancia de las normas jurídicas constitucionales de carácter social que tienen como principal propósito el aminorar las asimetrías: sociales, económicas, educativas, políticas e ideológicas. A fin de hacer menos desiguales a los desiguales, por medio de políticas públicas que permitan fortalecer la seguridad social. Lo cual, se refleja en mayor presupuesto para el desarrollo de la educación, ciencia y tecnología; vivienda, salud, empleo, etcétera. Consecuentemente, habrá menor presencia de escenarios caóticos que se cristalicen en conflictos sociales armados, que ponen en peligro la paz social, la seguridad y certeza jurídica. Empero, a mayor presencia de los lineamientos de la política económica liberal o neoliberal - mayor alejamiento del cumplimiento de los postulados del constitucionalismo social — con las consecuencias inminentes de problemas de conflicto social, tal fue el caso de la revolución mexicana, motivada por tanta desigualdad económica y social que ponen en peligro la paz social, la seguridad y certeza jurídica en México. Actualmente, un efecto de dicha problemática se expresa con la presencia del crimen organizado y el combate 
de éste, que han costado más de 48, 000 muertos según la versión oficial, otras fuentes mencionan más de 70 mil muertos.

De ahí que la política social tiene que visualizarse como construcción de igualdad, de justicia distributiva. Como plantea Bustelo, no se puede seguir planteando un "social" como simulacro: lucha contra la pobreza; metas para erradicarla; trabajo con los pobres; compromiso con los pobres, mientras aumenta la desigualdad y las disparidades. Uno de los resultados más perversos de la implantación de gobiernos neoliberales en nuestros países, es que en las estructuras gubernamentales (sin tomar en cuenta las áreas administrativas ni las asociadas con la seguridad o los procesos electorales) se ha producido una escisión tajante: por una parte, los que se ocupan de lo social y de la pobreza; por la otra quienes se ocupan de lo económico; éstos tienen prohibido pensar en objetivos como igualdad, reducción de la pobreza, protección de la población. Su criterio casi único es la eficiencia y a veces, el crecimiento. Se va desarrollando en esas áreas una insensibilidad social total, sin estimar criterios de bienestar social. ${ }^{11}$

Aunque actualmente existe un amplio acuerdo sobre la necesidad de poner fin a la pobreza, las discrepancias en el plano internacional sobre la mejor manera de alcanzar tal fin siguen existiendo. En particular, cada vez es mayor la incompatibilidad entre las políticas que persiguen Estados Unidos y las instituciones de Bretton Woods (como son el Banco Mundial y el Fondo Monetario Internacional [FMI]) y las políticas de la Unión Europea. ${ }^{12}$

Durante cuarenta años, el Banco Mundial, el FMI y otros organismos de la ONU han estado proponiéndose como objetivo lo que básicamente constituye el mismo conjunto de políticas para combatir la pobreza (Towsend y Gordon, 2000), que consta de tres elementos:

- crecimiento económico de base amplia

- desarrollo de capital humano, fundamentalmente por medio de la educación

- redes mínimas de protección social para los pobres ${ }^{13}$

11 Boltvinik, Julio y Damián, Araceu, “Introducción. La necesidad de ampliar la mirada para confrontar la pobreza", Pobreza en México y el mundo. Realidades y desafios, México, Siglo XXI Editores, 2004, p. 41.

12 Idem.

13 Ibidem, p. 46. 
Estas políticas no han tenido éxito. El número de pobres en el mundo ha ido en aumento y, en particular, las políticas mencionadas han tenido terribles consecuencias en muchas partes del África subsahariana, en América del Sur y en los países de la ex Unión Soviética. En parte, fracasaron debido a su inflexible adhesión a la ortodoxia de la economía neoliberal:

privatización: la cual tiende a elevar los precios para los pobres;

- liberalización del mercado de capitales: lo que le permite a los especuladores desestabilizar las economías nacionales, como sucedió ya en Asia y en América del Sur;

- precios basados en el mercado: esto aumenta los costos de alimentos básicos y combustible para los pobres, y con frecuencia ha sido la causa de disturbios, sobre todo en América del Sur (por ejemplo, Bolivia, Ecuador y, recientemente, Argentina). Los economistas no deberían andar provocando disturbios por el mundo; ${ }^{14}$

- libre comercio: éste se encuentra regido por la Organización Mundial de Comercio (OMC), que suelen colocar en situación de peligrosa desventaja a los países más pobres. ${ }^{15}$

La pobreza es la principal razón por la que no se vacuna a los bebés, por la que se carece de acceso al agua potable y a los sistemas de eliminación de excretas, por la que no se dispone de medicamentos y otros tratamientos terapéuticos y por la que muchas madres mueren en el momento de dar a luz. La pobreza es la causa principal de la reducción de la esperanza de vida, de las desventajas y las discapacidades, y de la muerte por hambre. La pobreza es el principal factor que contribuye a la enfermedad mental, al estrés, al suicidio, a la desintegración familiar y al consumo de drogas (OMS, 1995). ${ }^{16}$

Hace mucho que el género humano sueña con erradicar la pobreza de la superficie de la tierra. Las hermosas palabras y los intentos fallidos para alcanzar esta tarea han sido numerosos. Desde la antigua y milenaria pre-

${ }^{14}$ Idem.

15 Nota: véanse, por ejemplo, la ONG Social Watch de Uruguay (www.socialwatch. org), u Oxfam del Reino Unido (www.oxfam.org.uk/wto), así como Watkins y Fowler (2002). A pesar de las ventajas del libre comercio, la historia ha mostrado que sus resultados han sido a menudo graves hambrunas y pobreza creciente (PNUD, 1999; Davis, 2001). Citado por Boltvinik, Julio y Damián, Araceu, op. cit., p. 46.

${ }^{16}$ Ibidem, p. 70. 
sencia de la secta judía conocida con el nombre de los esenios, quienes habían renunciado a toda propiedad personal, no podían tener oro y plata, ni en particular tierras ni casas, las cuales eran comunes y tenían acceso hasta los extranjeros, no practicaban el comercio puesto que, se despertaría la afición al lucro y al deseo de dañar al prójimo. ${ }^{17}$

En México, han transcurrido más de 30 años, y las recetas monetaristas - del Fondo Monetario Internacional y Banco Mundial, por medio de las políticas neoliberales - traducidas en recortes al gasto público social e inobservancia de los principios que enmarcan al constitucionalismo social mexicano, no han logrado corregir la desigualdad en la distribución del ingreso y la riqueza, sino que, se ha acrecentado durante el presente 2012.

En el caso de México se estima que 82.37 millones de mexicanos tienen al menos una carencia social, como puede ser rezago educativo, salud, seguridad social, vivienda, servicios básicos en la vivienda y alimentación. ${ }^{18}$

Para garantizar la "equidad social" es necesario contar con los recursos suficientes para financiar su implementación universal más allá de una mera prestación y ciertamente que se requiere de voluntad política. ${ }^{19}$

Consecuentemente, cabe preguntar lo siguiente: ¿de qué sirve contar con el derecho de acceso a la justicia si no es efectivo? ¿Cómo se puede garantizar ese derecho en sociedades con altas cifras de pobreza, desigualdad y corrupción como la latinoamericana? La solución a esta problemática social trasciende Io estrictamente jurídico. De ahí que la perspectiva del acceso a la justicia hoy en día sea motivo de reflexiones desde los más diversos ángulos, como el de la sociología, la economía, la ciencia política, la psicología, la antropología, etcétera, cuestiones que no deben ser ajenas al análisis jurídico. ${ }^{20}$

17 Cfr. González Díaz Lombardo, Francisco, Compendio de historia del derecho y del Estado, México, Limusa, 1975. p. 82.

18 Metodología para la medición de la pobreza, México, Consejo de Evaluación de la Política Nacional, 2009. Citado por Hernández, María del Pilar, "Vivienda", Fix-Zamudio, Héctor y Valadés, Diego (coords.), Instituciones sociales en el constitucionalismo contemporáneo, 2a. ed., México, UNAM, Instituto de Investigaciones Jurídicas, 2011, p. 182.

19 Flores, Imer B., "Equidad social", ibidem, p. 162.

20 Una panorámica del acceso a la justicia en México desde una perspectiva multidisciplinaria, puede verse en Fix-Fierro, Héctor, y López Ayllón, Sergio, "El acceso a la justicia en México. Una reflexión multidisciplinaria”, en Valadés, Diego, y Gutiérrez, Rodrigo (coords.), Justicia. Memoria del IV Congreso Nacional de Derecho Constitucional, 
Así pues la justicia social implica avanzar de la igualdad ante la ley a la igualación ante la justicia. ${ }^{21}$

La marginación económica y social de la población en México ha sido uno de los obstáculos principales para la consolidación y efectividad del derecho de acceso a la justicia. ${ }^{22}$

El paradigma neoliberal supone el equilibrio de los mercados a través de la oferta y la demanda de los precios. Sin embargo, dicho modelo choca con la realidad histórica concreta a través de la existencia de los monopolios, oligopolios, ${ }^{23}$ duopolios,${ }^{24}$ bajo la supuesta estrategia de la optimización de los recursos económicos, aplicando esquemas orientados por los criterios de la eficacia y eficiencia de los mismos. Dando prioridad al individualismo pragmático, utilitarista, reforzado por las leyes del mercado y de la competencia. Por lo tanto, pasa al primer plano, la acumulación del capital. Así pues, para el modelo neoliberal no interesan el bien común, y menos aún, las necesidades existenciales, ni el derecho al desarrollo de los sectores populares. Incuestionablemente, para los interesados de este paradigma económico están de sobra todas aquellas disposiciones normativas que regulan los derechos y deberes sociales, económicos, y culturales a que tienen derecho a gozar y ejercer todas las personas, en especial, los que se encuentran carentes de lo mínimo nece-

México, UNAM, t. 1, 2001, pp. 111-142. Citado por Ferrer Mac-Gregor, Eduardo, "La justicia y el constitucionalismo social", ibidem, pp. 111 y 112.

$21 C f r$. Sobre este enfoque, véase Berizonce, Roberto O., Efectivo acceso a la justicia. Propuesta de un modelo para el Estado social de derecho, La Plata, Librería Editora Platense, 1987. Citado por Ferrer Mac-Gregor, Eduardo, "La justicia y el constitucionalismo social”, en Fix-Zamudio, Héctor y Valadés, Diego (coords.), op. cit., p. 112.

22 Cfr. Panorama social de América Latina, Santiago, Naciones Unidas-Cepal, 2010, pp. 11 y ss. Citado por Ferrer Mac-Gregor, Eduardo, op. cit., pp. 114 y 115.

23 Del griego oligo=pocos, polio=vendedor es una forma de mercado en la cual éste es dominado por un pequeño número de vendedores, significa pocos vendedores. Su posición ejerce un poder de mercado provocando que los precios sean más altos y la producción sea inferior; evitando así la competencia, creando un alto grado de interdependencia entre las decisiones de las empresas, http://es.wikipedia.org/wiki/Oligopolio.

24 Situación de mercado en que hay solamente dos oferentes de un determinado bien o servicio. Las acciones de una empresa afectarán la posición de precios y de mercado de la otra, no pudiendo un oferente predecir las consecuencias de sus propias acciones a menos que sea capaz de predecir las reacciones de su competidor. Usualmente, los duopolistas cooperan entre sí creando de hecho un monopolio, en que existen solamente dos demandas de un bien o servicio. Fuente de información: http://www.eco-finanzas.com/ diccionario/D/DUOPOLIO.htm. 
sario. Al respecto, los siguientes artículos: 3o., 4o., 5o., 25, 26, 27, 28, 29 y 123 de la Constitución Política de los Estados Unidos Mexicanos.

\section{II. ¿QUÉ ENTENDEMOS POR CONSTITUCIONALISMO SOCIAL?}

Previamente al desarrollo de este apartado, cabe hacer mención ¿Qué se entiende por constitución?, a este respecto, León Cortiñas Peláez, considera:

La Constitución como cultura no es solamente un texto jurídico o una obra de reglamentación normativa, sino que también es la expresión de una situación de desarrollo cultural, medio del autorretrato cultural de un pueblo, espejo de su herencia cultural y fundamento de esperanzas (...). Las Constituciones vivas como una obra de todos los intérpretes de Constituciones de la sociedad abierta son, respecto a la forma y al contenido, la expresión y divulgación de la cultura, un marco para (re) producir y de recepción cultural y almacén para las informaciones, experiencias y conocimientos culturales adquiridos. La Constitución es una forma creada que se desarrolla con la vida. ${ }^{25}$

Por lo que respecta al estado de derecho, es prudente expresar que dicho paradigma aparece con el desarrollo de las constituciones liberales, y que a continuación se mencionan:

El Estado liberal se desarrolló en Inglaterra a partir del siglo XVII ("Revolución Gloriosa", 1688-1689), consolidándose progresivamente en Europa después de la Revolución francesa (1789) y en los Estados Unidos a partir de la guerra de independencia (1776).

Las Constituciones francesas del periodo revolucionario dejaron huellas profundas en todo el desarrollo constitucional sucesivo.

La "Declaración de los Derechos del Hombre y del Ciudadano" de 1789 influyó a las sucesivas Constituciones de muchos países que la acogieron textualmente.

La Constitución de 1791, que contemplaba la forma monárquica, inspiró a la Constitución española (llamada de Cádiz) de 1812, que sirvió de modelo en Italia a los movimientos revolucionarios de 1821, y a la Constitución de Noruega de 1814, que a pesar de las sucesivas adecuaciones todavía está vigente.

25 Cortiñas Peláez, León, "La investigación científica constitucional de un alma gemela de Pablo Lucas Verdú (El derecho del más fuerte en la entraña del orden neoliberal)", Estudios de teoría del Estado y derecho constitucional..., cit., p. 197. 
La Constitución jacobina del año I (1793), no aplicada, sin embargo tuvo una influencia importante en el desarrollo de las ideas políticas, en cuanto se inspiró en una democracia directa y radical basada en la voluntad popular y asamblearia, y por primera vez enunció los "derechos sociales" (derecho al trabajo y a la instrucción) que se replantearán por la Constitución mexicana de 1917 y alemana de 1919. Esta Constitución suministrará también, el esquema organizativo de referencia a las soluciones adoptadas por las Constituciones soviéticas a partir de $1918 .{ }^{26}$

Ahora bien, con la aparición de las primeras constituciones liberales emerge el Estado de Derecho que choca con el absolutismo afirmado en los siglos precedentes en los Estados nacionales europeos, era la limitación del absolutismo del soberano y la conquista de un sistema de garantías frente al poder político. En este sentido, la ideología, que luego se definiría como liberal, fundaba sus raíces en la historia europea. A título ejemplificativo pueden recordarse las autonomías municipales en la Edad Media; la presencia en toda Europa de asambleas y de consejos representativos de los estamentos (clero, nobleza, burguesía); el valor de garantía atribuido a las costumbres constitucionales; el mantenimiento de una cierta autonomía de los jueces respecto del poder político, vinculándose la interpretación judicial a las antiguas costumbres del reino. También fue cierta la limitación de los abusos del absolutismo, merced a la concepción cristiana del valor de la persona humana, mientras que las luchas por la libertad religiosa en muchos países europeos sirvieron de premisa a más amplias libertades políticas. ${ }^{27}$

Si bien el constitucionalismo nace como el resultado de un profundo quiebre en el pensamiento político y jurídico moderno, ocurrido hace tres siglos, su construcción y evolución ha sido gradual y paulatina. Hoy en día, ante los retos que conlleva la globalización, el constitucionalismo requiere de una redefinición y, para ello, no hay mejor manera que entenderlo desde sus raíces, comprender los objetivos primarios que persigue y pensarlo desde una perspectiva histórica. ${ }^{28}$

26 Vergottini, Giuseppe de, Derecho constitucional comparado, México, UNAM, Instituto de Investigaciones Jurídicas, 2004, pp. 206-215.

27 Ibidem, p. 221.

28 Córdova Vianello, Lorenzo, "Prólogo", Ruipérez, Javier, El constitucionalismo democrático en los tiempos de la globalización. Reflexiones rousseaunianas en defensa del Estado constitucional democrático y social, México, UNAM, Instituto de Investigaciones Jurídicas, 2005. p. XIII. 
Así pues, hablar del constitucionalismo significa hablar de una larga tradición del pensamiento que encuentra sus raíces en los primeros autores liberales del siglo XVII, de John Locke en adelante, y en las primeras batallas ideológicas libradas en contra del poder absoluto y sus sostenedores.

Consecuentemente, a lo largo de la historia del pensamiento político y jurídico podemos encontrar cuatro usos prevalecientes del concepto de Constitución. El primero es aquel que se refiere a la forma de gobierno mediante la que se estructura políticamente una sociedad determinada. Éste corresponde a la idea griega de politeia con la que Aristóteles, por ejemplo, identifica a los diversos tipos de gobierno en su estudio sobre las formas políticas de la Grecia clásica. La segunda acepción del concepto de Constitución es aquella que derivada de las tesis del institucionalismo, la concibe como la expresión y el equilibrio de las fuerzas políticas realmente existentes en una sociedad; para decirlo de otro modo, es la manera en la que se reflejan e interactúan los factores reales de poder. En términos generales este uso del término coincide con el concepto de Constitución material que encuentra su definición más acabada en autores como Ferdinand Lassalle y, principalmente, en Maurice Hauriou y Santi Romano. ${ }^{29}$ El tercer uso de la idea de Constitución es el que hace el juspositivismo y que la identifica con una norma positiva, la norma de mayor jerarquía del ordenamiento jurídico, de la que dependen en última instancia todas las demás y que, por ese hecho, constituye el fundamento de unidad y de validez del entero sistema jurídico. Se trata de la norma positiva que corona el sistema y que, en la lógica de Hans Kelsen, se encuentra inmediatamente debajo de la Grundnorm (que, en todo caso, no es ya una norma positiva sino presupuesta). El cuarto y último uso de este concepto es el que la identifica con un sistema de garantías para limitar al poder, en primer término al poder político. Esta concepción garantista de la idea Constitución, típicamente moderna, es la acepción usual del liberalismo político, y encuentra su formulación clásica en el artículo 16 de la Declaración de los Derechos del Hombre y del Ciudadano de $1789 .{ }^{30}$

${ }^{29}$ Córdova Vianello, Lorenzo, op. cit., pp. XIII y XIV.

30 De acuerdo con Norberto Bobbio, según el moderno constitucionalismo "el poder político en cualquiera de sus formas y en cualquier nivel, incluso el más alto, está limitado por la existencia de derechos naturales... de los cuales son titulares los individuos en particular antes de la institución de la sociedad civil, y por las leyes constitucionales, que están garantizadas por la separación y por el control recíproco de los poderes que ejercen 
El Estado de derecho contrasta con todo poder arbitrario y se contrapone a cualquier forma de Estado absoluto o totalitario (Como ocurre con el llamado "Estado de policía) que, lejos de proponerse el mantenimiento del orden jurídico, se caracteriza por otorgar facultades discrecionales excesivas a la administración para hacer frente a las circunstancias y conseguir los fines que ésta se proponga alcanzar. ${ }^{31}$

Para L. A. Hayek, la idea del Estado de derecho, significa que el gobierno está vinculado por normas fijadas y publicadas de antemano — normas que hacen posible prever, con bastante certeza, cómo usará la autoridad sus poderes coercitivos en determinadas circunstancias y planear los asuntos de los individuos con base en este conocimiento. ${ }^{32}$

La función del legislador en una sociedad libre, sometida al estado de derecho, es crear y mantener las condiciones que defiendan la dignidad del hombre como individuo. Esta dignidad requiere no sólo conocimiento de sus derechos civiles y políticos, sino, también, el establecimiento de las condiciones sociales, económicas, educativas y culturales que son esenciales para el completo desarrollo de su personalidad.

El sentido literal del Estado de derecho, tiene dos aspectos: 1) las personas deben ser regidas por el derecho y deben obedecerlo, y 2) el derecho debe ser de tal manera que la gente pueda: ser guiada por él. El derecho debe ser susceptible de ser obedecido. Una persona se conforma al derecho en tanto no lo viola. Por tanto, si el derecho debe ser obedecido tiene que ser capaz: de guiar el comportamiento de sus súbditos. Encontrar lo que es y actuar con base en él. ${ }^{33}$ Consecuentemente, las disposiciones jurídicas deben ser relativamente estables.

La independencia del Poder Judicial tiene que ser garantizada, por medio de la designación de jueces, garantía de inamovilidad, procedimientos de fijación de salarios y otras condiciones de su función hechas para garantizar que los jueces estén libres de presiones extrañas y sean independientes de toda autoridad salvo de la autoridad del derecho.

las funciones principales del gobierno de la sociedad”. Bobbio, N., Teoría generale della politíca, Turín, Einaudi, 1999, p. 194. Citado por ibidem, p. XIV.

31 Orozco Hernández, J. Jesús, Diccionario jurídico mexicano, t. II, E-H, México, Porrúa-UNAM, 1985, p. 110.

32 Raz, Joseph, La autoridad del derecho. Ensayos sobre derecho y moral, trad. y notas de Rolando Tamayo y Salmorán, México, UNAM, Instituto de Investigaciones Jurídicas, 1982, p. 263.

33 Raz, Joseph, op. cit., p. 264. 
Los tribunales deben ser fácilmente accesibles para asegurar el Estado de derecho. Largos términos, excesivas costas, etcétera, pueden efectivamente convertir el más ilustre derecho en letra muerta y frustrar la posibilidad de que alguien sea efectivamente guiado por el derecho. ${ }^{34}$

Por su parte, E. Mascitelli, al tratar el concepto de liberalismo, expresa:

El pensamiento liberal es la expresión política y cultural de la lucha llevada a cabo por la burguesía contra los residuos económicos y sociales del feudalismo y el absolutismo monárquico. Por tanto, expresa en el campo de las relaciones políticas y de la concepción del Estado, los principios del libre cambio económico y de la libre competencia sobre la base de los valores de la libertad individual en las relaciones entre el Estado y el ciudadano. ${ }^{35}$

Al respecto, A. Seldon, comenta: "El liberalismo económico no niega que el Estado tenga un papel a desempeñar en las cuestiones económicas, pero lo considera como una ayuda al proceso competitivo para que sea más efectivo". Sobre todo cuando se trata de dar satisfacción a los interese colectivos vía servicios públicos, $\mathrm{y}$, no pueden ser suministrados por el mercado. "De instrumento de emancipación de toda la humanidad, el pensamiento liberal se transformó progresivamente en instrumento de discriminación contra las clases inferiores y de manera particular contra la naciente clase obrera". ${ }^{37}$

Con el propósito de conservar, fortalecer y legitimar al sistema capitalista, se establecen algunas limitantes al Estado de derecho liberal, mediante la intervención del Estado, se regulan un mínimo de derechos sociales en favor de los sectores populares. Al respecto, Giuseppe de Vergottini, expresa:

El otro aspecto nuevo que caracteriza la transformación del Estado liberal es el paso del abstencionismo dieciochesco a un intervencionismo progresivo. Una de las razones de fondo de este radical cambio de dirección consiste en la variación del equilibrio entre las clases sociales: la presencia del proletariado anteriormente subalterno exige al Estado intervenciones en el campo cultural, social y económico para resolver los problemas que no eran advertidos por una burguesía tendencialmente autosuficiente y celosa de su

34 Ibidem, pp. 269 y 270.

35 Mascitelli, Ernesto et al., Diccionario de términos marxistas, 1a. ed. en español, Barcelona, Ediciones Grijalbo, 1979, pp. 232, 233 y 234.

36 Seldon Arthur y F. G. Pennance, Diccionario de economía, 3a. ed., Barcelona, Ediciones Oikos-tau, 1980, p. 327.

37 Idem. 
propia autonomía en tales ámbitos. Por lo tanto, al lado de las tradicionales libertades negativas, encaminadas a impedir las injerencias del Estado en las autonomías del individuo, emergen los llamados derechos sociales, que suponen el papel activo del Estado en satisfacer la exigencia de pleno desarrollo de la persona y la participación efectiva de los individuos y de los grupos en la formación de las decisiones políticas. ${ }^{38}$

El estado liberal en su máxima expresión se olvida de la distribución del ingreso y de la riqueza para todos. Así pues, ante las asimetrías sociales, económicas, educativas, etcétera, se genera un paradigma constitucional que establece normas jurídicas protectoras de las clases sociales marginadas. A fin de lograr el equilibrio en las relaciones sociales y evitar los conflictos sociales armados, como fue el caso de la Revolución Mexicana de 1910. A este respecto, el Jurista Mexicano Sergio García Ramírez, considera que: el derecho social es volver la mirada hacia los grupos y las clases; desconoce el primado de la autonomía de la voluntad, para abrazar el control social de la libertad; cercena los derechos absolutos, para reorientarlos en sentido social; acude en defensa del débil, la mujer, el niño, el trabajador, el campesino, el anciano, el enfermo, el arrendatario, introduce el dirigismo contractual y crea nuevos órdenes jurídicos: el laboral, el agrario, el de la seguridad social, derecho y deber de educación e intervención constante del poder público en la vida económica y social, el propósito tutelar provoca la socialización del derecho. De todo esto se sigue la existencia de un "constitucionalismo social", sustentado en el Estado de derecho social, regido por la justicia y no ya únicamente por la libertad. ${ }^{39}$ Es decir, lo más trascendente es la igualdad tanto formal como material de las personas.

El nuevo contenido de las Constituciones queda de manifiesto en el señalamiento de preceptos sobre relaciones laborales, propiedad relativa y socializada (o diversas formas de tenencia, aprovechamiento y disposición de los inmuebles), derecho del individuo a la asistencia y a la seguridad social, matrimonio y familia, derecho y deber de educación e intervención constante del poder público en la vida económica y social. ${ }^{40}$

Ahora bien, con el propósito de clarificar aún más el sentido y alcance que tiene el constitucionalismo social, cabe citar, al distinguido Jurista

38 Vergottini, Giuseppe de, op. cit., p. 221.

39 García Ramírez, Sergio, "Tres textos precursores en el constitucionalismo social", Boletín Mexicano de Derecho Comparado, núms. 2-3, México, 1969, p. 472.

40 Ibidem, p. 473. 
Mexicano de reconocimiento universal don Héctor Fix-Zamudio, quien expresa lo siguiente:

La Constitución federal mexicana de 5 de febrero de 1917 debe considerarse como un documento de transición entre el sistema clásico individualista y liberal de la carta anterior de 1857 y las tendencias socializadoras que se manifestaron en la primera posguerra, con el mérito indiscutible de haber sido la primera que incorporó en su texto a los derechos sociales de los trabajadores y de los campesinos, adelantándose a otras leyes fundamentales, como la alemana de Weimar de 1919, y la de la revolución rusa de 1918, que iniciaron el llamado constitucionalismo social. ${ }^{41}$

Tenemos la convicción de que el principio fundamental de la democracia social, tiene sus bases esenciales en el texto original de la Constitución federal de 1917, se ha desarrollado de manera paulatina, de acuerdo con el crecimiento económico, social y cultural de nuestro país, y se refleja en numerosas reformas a diversos preceptos de nuestra ley suprema, que de esta manera se ha transformado y modernizado para adoptar, con modalidades propias, los lineamientos del constitucionalismo occidental de la segunda posguerra, que ha desembocado en el llamado Estado de bienestar o Estado de derecho social.

El artículo 40 de la Constitución federal vigente, califica a nuestro ordenamiento como democrático, pero esta declaración fundamental no nos aclara el contenido del vocablo, puesto que no hace sino reproducir casi literalmente lo dispuesto por el precepto del mismo número de la carta federal de 1857.

Es evidente que, no obstante tratarse de disposiciones iguales, su significado ha variado considerablemente en su contenido, ya que el sistema democrático de la ley suprema anterior tenía un significado estrictamente político, de acuerdo con los lineamientos del llamado "Estado de democracia clásica", o "Estado liberal burgués", en tanto que, como lo hemos sostenido con anterioridad, nuestra Constitución vigente posee una proyección social de la cual carecía la carta de 1857 , si se toma en cuenta el texto vigente del artículo 3o., fracción I, inciso a, de la propia Constitución de 1917, reformado el 30 de diciembre de 1946, de acuerdo con la redacción

${ }^{41}$ Fix-Zamudio, Héctor, "El Estado social de derecho y la Constitución mexicana", La Constitución mexicana: rectoría del Estado y economía mixta, México, UNAM, Instituto de Investigaciones Jurídicas, 1985, p. 119. 
elaborada por el entonces secretario de Educación Pública y distinguido escritor, Jaime Torres Bodet. ${ }^{42}$

En efecto, al referirse a los lineamientos que deben regir la educación que imparta el Estado - Federación, estados y municipios- dispone que la misma debe ser: democrática: "considerando a la democracia no solamente como una estructura jurídica y un régimen político, sino como un sistema de vida fundado en el constante mejoramiento económico, social y cultural del pueblo". ${ }^{43}$

Por su parte, el distinguido constitucionalista mexicano Jorge Carpizo considera, que una carta fundamental para considerarla como democrática, es preciso que realmente: $a$ ) asegure con amplitud al individuo sus derechos fundamentales; b) le garantice un mínimo de seguridad económica, y c) no concentre el poder en una persona o grupo; es decir, que las funciones sean ejercidas efectivamente por diversos órganos y el sistema de partidos acepte el principio de pluralismo ideológico.

La transformación del Estado de derecho clásico, individualista y liberal, en una organización política y jurídica en la cual se reconoce la estructura grupal de la sociedad y la necesidad de armonizar los intereses de dichos grupos sociales, económicos, políticos y culturales, cada vez más complejos, a través de los principios de la justicia social. A fin de concretizar el Estado social de derecho democrático. ${ }^{44}$

La tesis y el aspecto más importante de nuestra Constitución es el de la justicia social. El constitucionalismo social actualmente sufre verdaderos embates en contra. En México también; por ello, es indispensable que nuestra Constitución continúe siendo la mejor fortaleza de la justicia social. Hay que luchar, y con todas las fuerzas, por la normatividad plena de esos artículos constitucionales... ${ }^{45}$

Un Estado Social de derecho que prescinde del pluralismo tiende aceleradamente al paternalismo, y de ahí a la adopción de formas dogmáticas de ejercicio de la autoridad. El orden jurídico no es sino una parte del orden social. La norma da forma a lo que deben ser prácticas cotidianas.

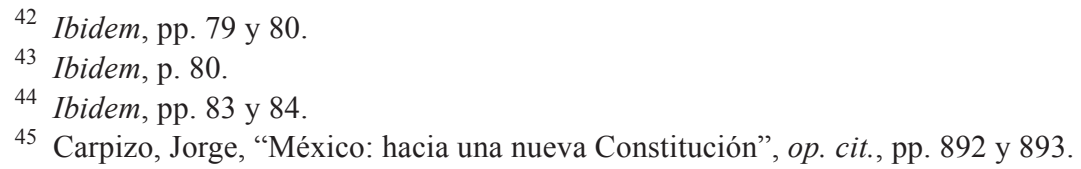


Cuando las prácticas reales no coinciden con su aspecto formal, la norma no sirve. ${ }^{46}$

La igualdad de oportunidades» ha pasado a erigirse en el presupuesto insoslayable para el tránsito de la democracia política a una «democracia social». En esa línea de pensamiento, no parece suficiente la proclamación de la igualdad legal como igualdad formal, sino que se reclama la toma de decisiones que favorezcan gradualmente la creación de condiciones generales en las cuales prospere el mayor grado posible de igualdad real de oportunidades. No se pretende que todos sean iguales ni que tengan o hagan lo mismo, pero se aspira a que las transformaciones sociales se orienten hacia la remoción de todos aquellos obstáculos, de hecho y de derecho, que impiden ese acceso del mayor número a las mejores oportunidades. Y, de esa manera aminorar las conductas antisociales.

El Estado de derecho tiene como finalidad específica la protección de la personalidad y sus inalienables derechos subjetivos. Para ello utiliza cuatro técnicas fundamentales, que son, a saber: a) el principio de la división de poderes, como medio para evitar su concentración en las manos de pocos detentadores; $b$ ) la sujeción del poder público al ordenamiento jurídico (principio de legalidad); c) la responsabilidad del Estado cuando, por su conducta lícita o ilícita, daña el patrimonio físico o moral de los administrados, y $d$ ) existencia de un control autónomo de legalidad (jurisdicción contencioso-administrativa). ${ }^{47}$

Habida cuenta, a las consideraciones antes mencionadas, estimo al igual que otros estudiosos, que el Constitucionalismo Social representa el paradigma jurídico que surge y evoluciona en y para beneficio de la sociedad en su conjunto, toda vez, que gracias a este modelo jurídico de organización social y política, se logran armonizar y aminorar los antagonismos y contradicciones de las clases sociales representados, por una parte, por los desamparados que carecen de lo mínimo necesario en relación con aquellos pequeños sectores de la sociedad que poseen todo y en abundancia. Así, en el Estado de derecho social democrático orientado y organizado a través

46 Valadés, Diego, Constitución y politica, 2a. ed., México, Facultad de Derecho de la Universidad Complutense de Madrid-España-UNAM, 1987, pp. 64 y 294.

47 Vanossi, Jorge Reinaldo A., "Horizontes humanos en el conocimiento, la cultura y la democracia", Estudios de teoría del Estado y derecho constitucional..., cit., p. 1973. 
del constitucionalismo social, se establecen estrategias para alcanzar los valores y fines que tienen que ver con la justicia social.

Para la distinguida especialista del derecho social, Patricia Kurczyn, nos expresa la siguiente reflexión:

La seguridad social significa la realización efectiva de los derechos sociales a través de la aplicación de los principios de la justicia distributiva, como la realización de la justicia legal material a través del Estado de derecho social, entendido éste como la fórmula para preservar la libertad a través de la dignidad humana. Los derechos sociales constituyen a la vez formas legales para generar prestaciones sociales que el individuo necesita, o que puede necesitar, para llevar una vida digna. Los derechos sociales se conducen a través de instituciones, una de las cuales es la seguridad social, cuya importancia merece que se eleve al rango mayor de la jerarquía normativa. Son derechos humanos prestacionales. ${ }^{48}$

Por su parte, Marcos Kaplan, destacado jurista y politólogo especialista en derecho económico, considera que:

El Estado democrático de derecho no implica un cuestionamiento de la existencia y rectoría del Estado. La reafirmación de su papel rector, su democratización en permanente ampliación y profundización, la redefinición de sus relaciones con la sociedad civil en el mismo sentido, confluirían en otorgarle legitimidad y consenso, capacidades incrementadas de decisión y acción, flexibilidad y eficacia mayores. Como institucionalización políticojurídica del poder popular, el nuevo Estado democrático de derecho estaría en mejores condiciones para realizar una estrategia de desarrollo integral, avanzar hacia formas superiores de sociedad y sistema político, por libre determinación y con plena participación de la población. Los mismos supuestos y mecanismos permitirían al Estado adoptar y aplicar formas de acción hacia afuera, que combinarían objetivos de autonomía nacional, mayor participación en las modalidades y logros de cooperación e integración latinoamericanas, y contribución efectiva a la emergencia de un nuevo orden mundial más libre y justo. ${ }^{49}$

48 Kurczyn Villalobos, Patricia, "Seguridad social", Fix-Zamudio, Héctor y Valadés, Diego (coords.), op. cit., pp. 196 y 197.

49 Kaplan, Marcos, "Rectoría del Estado y desarrollo en América Latina", La Constitución mexicana..., cit., pp. 52 y 53 . 


\section{GÉNESIS Y DESARROLLO DEL CONSTITUCIONALISMO SOCIAL} EN AMÉRICA LATINA

Los Estados que conforman a la América Latina comparten procesos históricos similares, entre otros cabe hacer mención de los siguientes: Durante tres siglos fueron sometidos bajo el esquema de colonias, ya sea de España o Portugal. Consecuentemente, presentan causas comunes que les permiten iniciar su lucha independentista.

- Con el desarrollo de la Revolución Industrial europea se da una expansión de los mercados internacionales generando una economía mundial.

- El pensamiento de los teóricos del enciclopedismo y de la ilustración, fortalecen las ideas liberales que darán sustento a las constituciones liberales propias del capitalismo de finales del siglo XIX.

- Con la caída de las monarquías absolutas propias del feudalismo se genera, el fortalecimiento de la burguesía y de la aparición de las clases medias.

- Socialmente aparece un proletariado urbano que requiere de la presencia de un Estado comprometido con los servicios públicos.

- La influencia del pensamiento social de intelectuales mexicanos de finales del siglo XIX, de la talla de Mariano Otero, Ponciano Arriaga, Ignacio Ramírez el Nigromante, etcétera.

- La Revolución mexicana de 1910, que tuvo un costo de más de 2 millones de muertes.

- Los Derechos Sociales Consagrados en la Constitución Política de los Estados Unidos Mexicanos de 1917, a través de los artículos: 3o., 4o., 5o., 25, 26, 27, 28 y 123.

A continuación, se hace referencia breve de algunos escenarios históricos que contextualizan la aparición y surgimiento del Constitucionalismo en América Latina.

Al respecto, el jurista guatemalteco, Jorge Mario García Laguardia, considera lo siguiente:

El desarrollo de la economía mundial proporcionó a los liberales la posibilidad de formar una infraestructura económica necesaria para que sus principios se implementaran en el área. La revolución industrial se presenta en 
la primera mitad del siglo XIX como un fenómeno exclusivamente inglés y concentrado en la industria textil. Pero a mediados del siglo se produce una expansión de la economía mundial, en la que influye significativamente el desarrollo de los transportes. El aumento de la capacidad económica en el mundo, provocó demanda de artículos suntuarios y muchas regiones de América Latina se vincularon al mercado internacional como "economías de sobre mesa", azúcar, tabaco, café...

Después de periodos autoritarios que producen vados constitucionales que se aprovechan para dictar con profusión decretos, leyes, a través de los cuales se realiza la reforma, se dictan varias constituciones que recogen el viejo ideario de la independencia en el nuevo contexto: separación de iglesia y Estado, enseñanza laica, libre testamentificación, reconocimiento del matrimonio civil y el divorcio, cementerios civiles, prohibición de vinculaciones, abolición de órdenes religiosas, desarrollo amplio de los derechos de inspiración iusnaturalista, división de poderes en un sistema unicameral, con fuerte preponderancia del ejecutivo. Guatemala (1879), Salvador (1886), Honduras (1880), Nicaragua (1893). ${ }^{50}$

Los movimientos sociales del siglo XIX y el crecimiento acelerado que se produce en los primeros años del siglo XX, obligan a replantear la propia razón de ser del Estado, orientándose al reconocimiento de su cada vez mayor intervención en la vida social. Junto al fortalecimiento de las libertades individuales, se produce la institucionalización de las libertadesparticipación, que obligan al Estado a intervenir en la vida social y política en un sentido protector. Los derechos económico-sociales son aceptados y además de convertirse el Estado en árbitro de las relaciones entre el capital y el trabajo, pretende intervenir en la cultura y la familia, imprimiendo fuertes limitaciones a los clásicos derechos individuales en aras del bienestar colectivo en una gran "tentativa de racionalización de la vida pública". Así aparece una gran corriente desde la Primera Guerra, que se acentúa después de la Segunda, que tiende a la constitucionalización de los derechos sociales. Que se inicia precisamente con un texto americano del área, la Constitución mexicana de 1917, pero que adquiere resonancia universal con la promulgación de la Constitución rusa de 1918 y especialmente con la alemana de Weimar de 1919, dentro de cuya tendencia deben incluirse las cartas fundamentales de España de 1931 — que tanta influencia tendrá

50 García Laguardia, Jorge Mario, "Evolución del constitucionalismo social en Centroamérica y Panamá", Boletín Mexicano de Derecho Comparado, México, núm. 20, mayo-agosto de 1974, p. 10. 
en América Latina - de Austria y Checoslovaquia de la primera posguerra y de la soviética de $1936 .{ }^{51}$

Ahora bien, a partir de principios del siglo XX, se produjo un cambio visible en América Latina, sobre la transformación en su estructura económica, en el aspecto social, aparecimiento de un incipiente proletariado urbano y una ampliación realmente inusitada de la clase media, que produce una movilidad vertical que sustituye el inmovilismo del periodo anterior, en el que los sectores medios solamente constituían una limitada capa que separaba a la élite dirigente decimonónica de la masa popular desorganizada. En lo político, se produce un proceso de transferencia del poder de la vieja aristocracia terrateniente a la clase media y a la incipiente burguesía urbana, lo que obliga a institucionalizar una política de intervencionismo de Estado, que se fortalece en la crisis de 1930. El aumento significativo de la población, ampliación de los servicios educativos y desarrollo cuantitativo y cualitativo de la administración pública que genera una burocracia especializada y en proceso de autonomía. Y finalmente, se inicia el surgimiento de los movimientos políticos de corte socialista. El anarquismo, traído por los inmigrantes europeos, influyó mucho en la incipiente organización sindical y los primeros partidos marxistas se fundan en la década de 1920-1930; en 1929 eran tan fuertes que celebraron la primera Conferencia Comunista Latinoamericana en Buenos Aires - la ciudad de más desarrollo industrial y de más inmigración obrera europea- con asistencia de 38 delegaciones. ${ }^{52}$

El Estado social de derecho significa en cambio, un aumento del poder en beneficio de la igualdad, más que de la propiedad y de la libertad. Su finalidad es repartir y utilizar al máximo los recursos de la comunidad en provecho del que más necesita. Las técnicas del Estado Social están en los servicios públicos, en las prestaciones de socorro a ciertos grupos o de fomento de ciertas actividades y, sobre todo, en las políticas económicas del Estado, sobre precios, moneda, crédito y hacienda pública (básicamente tributaria). ${ }^{53}$

El denominado "constitucionalismo social" registra tres etapas en su evolución: en su primera etapa comprendió la inserción de cláusulas

${ }^{51}$ Ibidem, p. 12.

52 Idem.

${ }^{53}$ Hernández Valle, Rubén y Villegas Antillón, Rafael, "El constitucionalismo costarricense en los últimos setenta años", El constitucionalismo social en las postrimerías del siglo XX, Las constituciones latinoamericanas, México, UNAM, Instituto de Investigaciones Jurídicas, 1988, t. III, pp. 180 y 181. 
económicas y sociales en los textos constitucionales (referentes a la propiedad, a la tierra, al trabajo, etcétera) y en una segunda etapa abarcó la protocolización expresa de los nuevos roles del Estado (un Estado activo, intervencionista, provisor o «de bienestar»), en la última etapa - que es la contemporánea - asistimos a la consagración de un constitucionalismo social de la cultura y de la educación. La perspectiva social es lo único que hoy mantiene el sentido de la democracia para vastos sectores de la sociedad. Así como los derechos sociales - incluidos los de la cultura y de la educación - pasa a desempeñar el importantísimo sentido y significado de asegurar las condiciones reales de existencia y funcionamiento de una democracia política efectiva.

Por ello, la democracia social se convierte en re aseguro de la paz en el seno de la comunidad al posibilitar el goce de los derechos por el mayor número y la reducción a su más mínima expresión de los sectores que actúan como grupos de tensión. ${ }^{54}$

Igualmente, cabe resaltar que en América Latina la iglesia católica, jugó un papel importante en la aceptación y difusión del pensamiento social, a este respecto, cabe señalar lo siguiente:

Los opositores los tildaron inmediatamente de "comunistas", a lo que respondió en forma muy hábil monseñor Sanabria con la siguiente frase: "Me asustan los caminos de la izquierda, pero nunca me han asustado los caminos de la justicia".

\section{La Encíclica Quadragesimo Anno:}

los hombres deben tener en cuenta, no sólo de su felicidad, sino también del bien común, como se deduce de la índole misma del dominio, que es a la vez individual y social. Por lo tanto la autoridad pública, guiándose siempre por la ley natural y Divina, e inspirándose en verdaderas necesidades del bien común, puede determinar más exactamente lo que es lícito o ilícito a los poseedores en el uso de sus bienes (Doctrina social, de G. C. Rutten, p. 269.) ${ }^{55}$

A partir de 1942 el Estado costarricense empezaría a intervenir, cada vez con mayor frecuencia, en los ámbitos económicos y so-

${ }^{54}$ Ibidem, p. 184.

55 Ibidem, pp. 184 y 185. 
ciales para garantizar ya no sólo la libertad de los administrados, sino fundamentalmente para tratar de lograr su igualdad material. ${ }^{56}$

El Estado procurará el mayor bienestar a todos los habitantes del país, organizando y estimulando la producción y el más adecuado reparto de la riqueza. ${ }^{57}$

Las nuevas orientaciones del constitucionalismo mundial son adoptadas, más que como producto de una lucha popular por obtenerlas, como concesión de la clase media en ascenso en busca de ampliación de sus bases de apoyo político y social: "insistiendo en que la política económica de los últimos cincuenta o sesenta años no había creado una vida nacional plena porque había sido concebida en el vacío, los nuevos dirigentes de los sectores medios prometieron no solamente el progreso económico sino también la democracia social. ${ }^{58}$

Los países centroamericanos: Belice, Guatemala, El Salvador, Costa Rica Nicaragua, Honduras y Panamá, en términos generales siguen las mismas líneas del desarrollo constitucional en el mundo.

Del análisis de las constituciones que a partir de 1920 se han promulgado en la región podemos inferir que el nuevo constitucionalismo se ha orientado por las siguientes tendencias:

1. Preocupación por la racionalización del poder.

2. Cambio en la filosofía general.

3. Recepción del derecho internacional.

4. Ampliación de catálogo de derechos individuales y constitucionalización de los sociales.

5. Ampliación de la democracia y racionalización del aparato político.

6. Ocaso del laicismo

7. Economía, hacienda, administración.

8. Justicia constitucional.

9. Semiparlamentarismo y preponderancia presidencial.

10. Inestabilidad. ${ }^{59}$

56 Ibidem, p. 186.

57 Ibidem, p. 187.

58 García Laguardia, Jorge Mario, op. cit., p. 13.

59 Ibidem, pp. 13-19. 
Al respecto, Humberto Quiroga Lavié, considera:

\begin{abstract}
al Estado social hay que definirlo como "Estado de prestaciones" sin desmedro del "Estado de libertades". El Estado se obliga para asegurar el equilibrio y desenvolvimiento estructural de cada nación, a falta de lo cual la crisis se toma desestabilizante. Son ingobernables los países apoyados en estructuras fracturadas por la debilidad que genera el hambre, la desnutrición, el analfabetismo y las epidemias: en Latinoamérica el mapa social está dibujado por agudos desequilibrios; la mano del Estado resulta insoslayable para impulsar la generación de nuevas energías, para evitar la pérdida o la huida de sus recursos propios y el no reciclaje de tanta riqueza abandonada a su suerte, así como para impulsar el ingreso de todos aquellos bienes o recursos que faltan en nuestras tierras. ${ }^{60}$
\end{abstract}

El Estado social en Latinoamérica como un orden económico constitucional, establece los principios estructurales y programáticos a partir de los cuales debe desarrollarse la política económica social en cada país.

Argentina, con la Constitución más antigua del continente, establece limitados principios de orden económico:

La potestad expropiatoria por causa de utilidad pública y previamente indemnizada (artículo 17), en el fomento de la inmigración europea (artículo 25), en el monopolio del Estado para hacer sellar moneda y fijar su valor, así como establecer un banco nacional (central); empero, a partir de la "cláusula de la prosperidad" (artículo 67.16), el Congreso puede proveer lo conducente al adelanto y bienestar de todas las provincias y al progreso de la ilustración, dictando planes y promoviendo (perfil permisivo de la intervención del Estado), la industria, la entrada de capitales y, en general, el desarrollo económico del país.

En Colombia, en la medida que la Constitución dispone que las autoridades también están instituidas para asegurar el cumplimiento de los deberes sociales del Estado, se ha impulsado el paso del Estado de derecho formal al Estado de derecho social, lo cual, en secuencia coherente conducirá al Estado de bienestar. ${ }^{61}$

60 Quiroga Lavié, Humberto, "Estudio introductorio", El constitucionalismo social en las postrimerías del siglo $x x, \ldots$, cit., p. 26.

61 Ortiz y Ortiz, Eduardo, "Las reformas a la Constitución de Costa Rica de 1949”, Evolución de la organización político-constitucional en América Latina (1950-1975), México, UNAM, Instituto de Investigaciones Jurídicas, 1978, vol. I, nota 4, p. 119. Citado por Quiroga Lavié, Humberto, op. cit. p. 28. 
En Latinoamérica la clase media ha venido manteniendo un consumo irracional sobre la base de importaciones de productos foráneos, a costa, con mucha frecuencia, de las clases pobres, de los marginados suburbanos sin educación y del sector campesino ignorante, todos los cuales no se encuentran en condiciones de formar partidos o grupos de presión que los defiendan. ${ }^{62}$

México, país pionero de la democracia social en el continente, establece la rectoría del Estado del desarrollo nacional para garantizar que éste sea integral, que fortalezca la soberanía de la nación y su régimen democrático y que, mediante el fomento del crecimiento económico, el empleo y una más justa distribución del ingreso y de la riqueza, permita el pleno ejercicio de la libertad y la dignidad de los individuos, grupos y clases sociales (artículo 25).

El Estado social como una programática constitucional o catálogos de ilusiones, pero que, no cabe duda cumplen, al menos, con la trascendente función de definir en el orden de las finalidades normativas, la identidad de nuestros pueblos y la conciencia de nuestras carencias e irrealizaciones.

Bien dice Pantoja Morán que "por profunda que sea la discrepancia entre norma y realidad, es incuestionable que aquélla es la idea del orden social deseable cuya vocación es positivizar el ideal de que es portadora...", ${ }^{63}$ “....y aunque se viole su espíritu, el hecho de que se conserve en letra es reconocimiento de la vigencia de esos ideales..." (Vicente Herrero).

En un comentario acerca del impacto social de la Constitución peruana de 1978, Domingo García Belaúnde afirma que la sociedad peruana vive con graves problemas económicos, desamparado en sus derechos fundamentales, sin lugar a dudas la Constitución responde a las aspiraciones de la sociedad: ella es más generosa en su ideario humanista. ${ }^{64}$

Las áreas prestacionales previstas en los textos constitucionales latinoamericanos están referidas a diversas materias, entre las cuales destacan: la protección de la salud, de la cultura, de la familia, de la ciencia y de la tecnología, el régimen de la reforma agraria, los de asistencia, seguridad y previsión social y la protección del deporte, materias todas ellas minuciosamente regladas que ameritan un estudio más detallado.

${ }^{62} C f r$, en tal sentido, Ortiz y Ortiz, Eduardo, ibidem, p. 29.

63 Pantoja Morán, David, La idea de soberanía en el constitucionalismo latinoamericano, México, UNAM, 1973, p. 8. Citado por ibidem, p. 32.

${ }^{64}$ Cfr. García Belaúnde, Domingo, Constitución y politica, Lima, 1981, p. 165. Citado por Quiroga Lavié, Humberto, op. cit., p. 32. 
En Brasil, hasta antes de la década de los 80 , ya se les reconoce a los indios su organización social, costumbres, lenguas, creencias y tradiciones. Y los derechos originarios sobre las tierras que tradicionalmente ocupan... (artículo 231); ...las riquezas del suelo, ríos y lagos allí existentes (artículo 231.2); dichas tierras son inalienables y los derechos sobre ellas imprescriptibles (artículo 231.4); está prohibida la remoción de los grupos indígenas de sus tierras..., salvo catástrofe o epidemia, previa intervención del Congreso... (artículo 231.5). ${ }^{65}$

A la minoría indígena se la trata como un objeto, como algo que debe ser mantenido en resguardo, en reserva, y que ha sido encomendado a alguien para que lo saque de su estado salvaje y lo dirija hacia la civilización" (estamos glosando una idea que ha obsesionado a Vargas Llosa en El Hablador)... El indígena sigue siendo algo semejante a una afrenta nacional... se procura excluido de todo contacto con los cuerpos civilizados. ${ }^{66}$

El reconocimiento de las acciones populares en Brasil, Perú, Colombia, se establece no para reparar intereses individuales sino colectivos, pues su objeto es anular el acto lesivo o ilegal y no indemnizar al accionante que no debe probar perjuicio alguno.

En Perú, se exige que sean 50,000 los ciudadanos que la interpongan en tal caso. ${ }^{67}$

Los Juristas Mexicanos Hector Fix Zamudio y Salvador Valencia Carmona, al referirse al Constitucionalismo Social, consideran:

Es ingenua la aceptación acrítica de los argumentos del libre mercado y la economía de la oferta, que como reacción al desencanto de la intervención del gobierno ha surgido en varios países. Ante la crisis actual de los paradigmas, se recomienda innovar, buscar la opción alternativa, que reconociendo el papel del orden económico, también admita "sus fallas y límites frente a deseconomías externas, bienes públicos, y frente a imperfecciones de mercado, como estructuras oligopólicas y monopólicas. Así como frente a los problemas de la distribución del ingreso", por ello, ante "el dilema entre el Estado mínimo y el Estado máximo, se propone llegar a un Estado óptimo".

65 Ibidem, p. 34.

66 Zea, Leopoldo, El Occidente y la conciencia de México, 1958, cit. por idem.

67 Quiroga Lavié, Humberto, op. cit., p. 36. El autor antes referido expresa que sobre esta temática puede consultarse su libro intitulado Los derechos públicos subjetivos y la participación social, Buenos Aires, Depalma, 1986. 
No existe, además, "un milagro del mercado que haga que la población y los recursos lleguen al equilibrio y los mantenga ahí", la competencia "por sí misma no puede funcionar sin un marco legal, político y adecuado, y los mercados competitivos no sobrevivirán los esfuerzos de los competidores mismos para eliminarlos sin la incesante vigilancia de los gobiernos". ${ }^{68}$

En relación con la intervención del Estado para aminorar las asimetrías, Marcos Kaplan, considera:

La experiencia histórica de América Latina en las últimas décadas demuestra una mayor o menor incapacidad para garantizar la rectoría del Estado, su efectividad y eficacia, especialmente en lo referente a la superación del atraso, de la dependencia externa y de la crisis; al logro de crecimiento económico, bienestar social para las mayorías, vigencia de los derechos humanos, plena participación democrática, preparación y lanzamiento de un proceso de desarrollo integral.

La experiencia histórica evidencia también que la rectoría del Estado es indispensable pero insuficiente, afectada por una grave crisis pero recuperable como transfiguración bajo las formas de un nuevo Estado democrático de derecho, un proceso de democratización permanente, expresado y realizado en nuevas formas y estructuras sociopolíticas de participación, de poder y autoridad, de legitimación y consenso, de relaciones entre el Estado y su sector público, la sociedad civil y sus sectores social y privado. ${ }^{69}$

\section{CONSTITUCIONES DE AMÉRICA LATINA QUE INCLUYEN EL CONSTITUCIONALISMO SOCIAL}

Dentro de la vasta normatividad que puede verificarse en las veinte constituciones latinoamericanas en relación con regulaciones de índole económica, vinculadas con la reivindicación del dominio público del Estado sobre zonas estratégicas, con el aseguramiento de la libre concurrencia en la actividad económica, con la intervención (directa o indirecta) del Estado en la economía, con la determinación de los sectores básicos de la economía, con el sistema financiero nacional, con la regulación de la empresa pública y de la obra pública, con la protección de la deuda pública (interna o ex-

${ }^{68}$ Fix-Zamudio, Héctor y Valencia Carmona Salvador, op. cit., p. 535.

69 Kaplan, Marcos, op. cit., p. 52. 
terna), con la regulación presupuestaria y de la banca central, así como de la emisión monetaria, sólo podemos detenerlos en recordar las previsiones referidas a la regulación del derecho de propiedad. ${ }^{70}$

En tal sentido recordamos que el derecho de propiedad ha sido colocado en toda Latinoamérica bajo la advocación de la función social o del interés general colectivo: Bolivia, Brasil, Colombia, Chile, República Dominicana, El Salvador, Haití México, Uruguay, Ecuador, Honduras, Panamá, Paraguay, Perú, dispone que la ley puede, por razones de interés nacional, establecer restricciones y prohibiciones especiales... sobre determinados bienes...; Costa Rica, Guatemala, Venezuela. Las únicas Constituciones que omiten calificar de social al derecho de propiedad son la argentina lo cual se explica por su orientación individualista - la cubana — lo cual también se explica debido a su carácter colectivista - y la nicaragüense, donde ello se explica.

La expropiación por necesidad, utilidad pública o por interés social declarado por ley, previa indemnización, encuentra reconocimiento en: Argentina, Brasil, Bolivia, Colombia, Costa Rica, Cuba, Chile, República Dominicana, Ecuador, El Salvador, Guatemala, Haití, Honduras, México, Panamá, Paraguay, Perú, Uruguay, Venezuela. En Panamá, Paraguay y Venezuela no se exige que la indemnización sea previa.

Resulta destacable que la única Constitución latinoamericana que no prevé la potestad expropiatoria es la de Nicaragua; tampoco se prohíbe allí la confiscación. Ello implica que la necesidad de ley e indemnización previa no están en ese país garantizadas por la Constitución, recaudo que consta, incluso, en el sistema colectivista cubano. ${ }^{71}$

El uso de la propiedad (no la expropiación en caso de inminente peligro público, con indemnización del daño, está contemplado en el Brasil.

\section{Argentina $^{72}$}

Del 22 de agosto de 1994, actualizada al 16 de julio de 2008 .

Consta de 129 artículos ordinarios 17 artículos transitorios.

Capítulo I. Declaraciones, derechos y garantías.

${ }^{70}$ Cfr. Quiroga Lavié, Humberto, Derecho constitucional latinoamericano, México, UNAM, Instituto de Investigaciones Jurídicas, 1991, pp. 80-103.

71 Ibidem, p. 30.

72 http://www.diputados.gov.ar/. Fecha de consulta: 01 de febrero de 2012. 
Artículos 14-17. Regulan el derecho al trabajo y la seguridad social, se prohíbe la esclavitud, no admite prerrogativas de sangre, de nacimiento, ni fueros personales ni títulos de nobleza, y establecen el derecho de propiedad.

Capítulo segundo. Nuevos derechos y garantías. Los arts. 41 y 42 establecen el derecho a un ambiente sano y el derecho de los consumidores y usuarios de bines y servicios a la protección de su salud y seguridad.

\section{Bolivia $^{73}$}

De febrero de 2009.

Consta de 411 artículos ordinarios 10 artículos transitorios.

Capítulo quinto. Derechos sociales y económicos, artículos 33 al 71, 75 y 76. Regulan el derecho al medio ambiente, a la salud, a la seguridad social, derecho al trabajo y al empleo, derecho a la propiedad, derechos de la niñez, adolescencia, juventud, derecho familiar, derechos de las personas adultas y mayores, derechos de las personas con discapacidad: social, educación, trabajo, discriminación o explotación, y derecho del consumidor.

Capítulo sexto. Educación, interculturalidad y derechos culturales, con cinco secciones, artículos 77 al 105. Regulan el derecho a la educación, interculturalidad, derechos culturales, ciencia tecnología e investigación, derecho al deporte y recreación, la comunicación social y la participación.

\section{Brasil $^{74}$}

De 1988, consta de 245 artículos ordinarios 70 artículos transitorios.

Capítulo segundo de los derechos sociales, artículo 6o. clasificación de los derechos sociales como educación, trabajo seguridad, previsión social, etcétera; artículos 7 y 8 derecho al trabajo y la libertad de asociación.

Artículo 9o. derecho a la huelga.

Artículos 10 y 11 derecho de representación de los trabajadores.

${ }^{73}$ http://www.redij.org/eleccionjuecesbolivia/wp-content/uploads/2011/07/NCPE_ constitucion-r.pdf. Fecha de consulta: 01 de febrero de 2012.

${ }^{74}$ http://www.acnur.org/biblioteca/pdf/0507.pdf. Fecha de consulta: 1o. de febrero de 2012. 


\section{Colombia $^{75}$}

De 1991, actualizada hasta el 2005.

Consta de 380 artículos ordinarios 60 artículos transitorios.

Capítulo segundo. De los derechos sociales, económicos y culturales y capítulo tercero, de los derechos colectivos y del ambiente", artículos 42-82.

Regulan: los derechos de familia, niños, adolescentes y personas de la tercera edad, derecho a la seguridad social, derechos de los disminuidos físicos, sensoriales y psíquicos, derecho a la salud y saneamiento ambiental, derechos del trabajo, derechos de propiedad, privada, agraria e intelectual, protección del Estado a la actividad agrícola, derecho a la ecuación, ciencia y tecnología, la protección del patrimonio cultural, el derecho a la información y el derecho al medio ambiente sano.

\section{Costa Rica ${ }^{76}$}

Del 7 de noviembre de 1949, actualizada al 2 de enero de 2009.

Consta 197 artículos y 13 artículos transitorios.

Título quinto. Derechos y garantías sociales, capitulo único, artículos 50-74, regulan el derecho al bienestar social, reparto de la riqueza y medio ambiente sano, derechos de la familia, derechos de los trabajadores y la irrenunciabilidad de estos derechos y beneficios. Título sexto capítulo único.

Artículo 75 regula el derecho a la libertad de profesar algún culto religioso.

Título séptimo capítulo único, artículo 76 establece el español como idioma oficial, el derecho a la educación y la protección de las bellezas naturales, el patrimonio histórico, artístico y científico.

La regla en los textos latinoamericanos es la prohibición de la confiscación: Argentina, Chile, Colombia, Costa Rica, República Dominicana, Ecuador, El Salvador, Guatemala, México, Panamá, Paraguay, Venezuela. Sin embargo, algunos países como Bolivia y Haití, al igual que con las nacionalizaciones de bienes en Uruguay, sólo la prohíben por causas políticas,

75 http://www.presidencia.gov.co/prensa_new/constitucion/index.pdf. Fecha de consulta: 01 de febrero de 2012.

76 http://www.asamblea.go.cr/Centro_de_Informacion/biblioteca/Paginas/Constitu ción\%20Política\%20de\%20Costa\%20Rica.aspx. Fecha de consulta: 1o. de febrero de 2012. 
de modo tal que se habilita la expropiación de la propiedad, no invocando dichas causas. ${ }^{77}$

\section{Cuba $a^{78}$}

Del 1o. de agosto de 1992, actualizada al 26 de junio de 2002.

Consta de 137 artículos ordinarios y 1 de disposición especial.

Artículos 19 y 20 establecen el derecho de los agricultores sobre sus propiedades y su derecho de asociación.

Capítulo cuarto. Familia, artículos 35-38 establecen los derechos a la familia.

Capítulo quinto. Educación y cultura, artículos 39 al 40 regulan el derecho a la educación, la cultura y las ciencias, derecho de la niñez y la juventud.

Capítulo séptimo. Derechos, deberes y garantías, artículos 45 al 55 regulan: los derechos al trabajo en la sociedad socialista, el derecho a la salud, derecho a la educación, al deporte y la recreación, la libertad de expresión, el derecho de reunión, manifestación y asociación, el derecho a la libertad de creencias religiosas.

\section{Chile $^{79}$}

Del 22 de septiembre de 2005.

Consta de 129 artículos ordinarios y 25 artículos transitorios.

Capítulo tercero. De los derechos y deberes constitucionales, artículos 19 y 20 , regulan derechos a la vida, integridad física y psíquica, igualdad, protección de derechos, familia, creencias y cultos, medio ambiente, educación, libertad de opinión, trabajo y el procedimiento para defender los derechos ya mencionados, mediante las apelaciones en la Corte.

77 Ibidem, p. 31.

78 http://www.cuba.cu/gobierno/cuba.htm. Fecha de consulta: 1o. de febrero de 2012.

79 http://www.poderjudicial.cl/PDF/LeyTransparencia/marcoNormativo/1.pdf?opc menu=3\&opc_item $=13$. Fecha de consulta: 1o. de febrero de 2012. 
República Dominicana ${ }^{80}$

Del 26 de enero de 2010.

Consta de 120 artículos ordinarios, 19 disposiciones transitorias y una disposición final.

Título segundo. De los derechos garantías y deberes fundamentales, capítulo I, de los derechos fundamentales, sección II, de los derechos económicos y sociales; artículos 50, 51, 53, 54, 56-63, regulan los siguientes derechos: libertad de empresa, derecho de propiedad, derechos del consumidor, seguridad alimentaria, protección de las personas menores de edad, de la tercera edad, con discapacidad, derecho a la vivienda, a la seguridad social, a la salud, al trabajo, a la educación.

Sección III. De los derechos culturales y deportivos, artículos 64 y 65 contienen los derechos culturales y deportivos.

Sección IV. De los derechos colectivos y del medio ambiente, artículos 66 y 67 establecen los derechos colectivos y difusos, y el derecho a la protección del medio ambiente.

\section{Ecuador $^{81}$}

Del 20 de octubre de 2008.

Consta de 444 artículos ordinarios y 30 artículos transitorios.

Título segundo. Derechos.

Artículos 10 y 11 establecen los principios de aplicación de los derechos.

Artículos 12 al 34 Regulan los siguientes derechos: derechos del buen vivir, del ambiente sano, derecho a la comunicación e información, cultura y ciencia, educación, hábitat y vivienda, salud, trabajo y seguridad social.

${ }^{80}$ http://www.procuraduria.gov.do/Novedades/PGR-535.pdf. Fecha de consulta: 10. de febrero de 2012.

81 http://www.asambleanacional.gov.ec/documentos/Constitucion-2008.pdf. Fecha de consulta: 3 de febrero de 2012. 
El Salvador ${ }^{82}$

Del 20 de diciembre de 1983, con reformas hasta el 30 de septiembre de 2011.

Consta de 249 artículos ordinarios 24 artículos transitorios 1 artículo de vigencia.

Sección tercera. Educación, ciencia, y cultura, capítulo II. Derechos sociales, con dos secciones, artículos 32-70 regulan derechos a la familia, derechos de los menores en las familias, ambientales, salud e igualdad, derechos del trabajo, a la seguridad social, derecho a la educación y cultura, establece el derecho a la salud y asistencia social.

\section{Guatemala $^{83}$}

Del 14 de enero de 1986 y reformada por acuerdo legislativo núm. 18-93 del 17 de noviembre de 1993.

Consta de 281 artículos ordinarios 27 artículos transitorios.

Capítulo II. Derechos sociales, con diez secciones, artículos 47-134 regulan derechos a la familia a menores, ancianos, minusválidos en su salud, seguridad, educación alimentación y previsión social, derecho a la cultura, derechos a las comunidades indígenas, derecho a la educación, derecho de las universidades, derecho al deporte, a la salud, seguridad y asistencia social, derechos del trabajo, derechos de los trabajadores del Estado, se establecen se establecen posprincipios económicos y sociales, la propiedad de los bienes nacionales al Estado y la descentralización y autonomía de los municipios.

Honduras $^{84}$

Del 20 de enero de 1982, actualizada hasta el 20 de enero de 2011.

Consta de 375 artículos ordinarios 3 disposiciones transitorias (376-378).

82 http://www.asamblea.gob.sv/eparlamento/indice-legislativo/buscador-de-docu mentos-legislativos/constitucion-de-la-republica. Fecha de consulta: 3 de febrero de 2012.

${ }^{83}$ http://www.larutamayaonline.com/constitucion/constitucion1.html.

${ }^{84}$ http://pdba.georgetown.edu/Constitutions/Honduras/vigente.html. Fecha de consulta: 3 de febrero de 2012 . 
Capítulo tercero. De los derechos sociales, artículos 111-118, regulan derechos a la familia, de los niños y los ancianos.

Capítulo cuarto. De los derechos del niño, artículos 119-126, regulan derechos del niño deficiente, se establece la jurisdicción especial, seguridad social y educación, protección contra el abandono, crueldad y explotación.

Capítulo quinto. Del trabajo, artículos 127-141, regulan derechos al trabajo.

Capítulo sexto. De la seguridad social, artículos 142-144, regulan el derecho a la seguridad social.

Capítulo séptimo. De la salud, artículos 145-150, regulan el derecho a la salud y al medio ambiente.

Capítulo octavo. De la educación y cultura, artículos 151-177, regulan el derecho a la educación, derechos de las culturas nativas, derechos de las universidades.

Capítulo noveno, artículos 178-181, regulan el derecho a la vivienda digna.

\section{México $^{85}$}

Del 5 de febrero de 1917, ultima reforma Diario Oficial de la Federación del 13 de octubre de 2011.

Consta de 136 artículos ordinarios y 17 artículos transitorios en su publicación original, actualmente, con la última reforma del 13 de octubre de 2011, es un artículo transitorio.

En el artículo 2o. regula los derechos de los pueblos indígenas. El artículo 3 regula el derecho a la educación. El artículo 4 establece el derecho de la familia a una vivienda digna y decorosa y a un ambiente sano. El artículo 5 establece el derecho a dedicarse a cualquier empleo o profesión lícita. El artículo 25 regula la rectoría del desarrollo nacional integral y sustentable. El artículo 26 regula el sistema de planeación democrática del desarrollo nacional y establece un sistema nacional de información estadística y geográfica. El artículo 27 regula el derecho agrario prohibiendo los latifundios y monopolios y establece la justicia agraria. Título sexto. El artículo 28 señala la prohibición de los monopolios, los estancos, y las exenciones de impuestos. El artículo 29 establece el procedimiento de suspensión de las garantías.

85 http://www.diputados.gob.mx/LeyesBiblio/pdf/1.pdf. Fecha de consulta: 3 de febrero de 2012. 
Título sexto. Del Trabajo y de la previsión social, el artículo 123 regula el derecho al trabajo, de los trabajadores de empresas privadas y trabajadores del Estado, y establece el derecho a la seguridad social.

Nicaragua ${ }^{86}$

Publicada y entrada en vigor en el 16 de septiembre de 2010.

Consta de 195 artículos ordinarios y 7 artículos transitorios, del 196-202.

Capítulo tercero. Derechos sociales, artículos 56-69, regulan los derechos de los discapacitados, el derecho al trabajo, a la educación, a la cultura, al medio ambiente, la seguridad social, al deporte y la recreación.

Capítulo cuarto. Derechos de la familia, artículos 70-79, regulan el derecho a la Familia (reproducción e igualdad entre los hijos).y los derechos de los ancianos.

Capítulo quinto. Derechos laborales, artículos 80-88, regulan el derecho al trabajo.

Capítulo sexto. Derechos de las comunidades de la Costa Atlántica, artículos 89-91, regulan los derechos de las comunidades indígenas (no discrimación y preservación).

\section{Panamá $^{87}$}

Del 11 de octubre de 1972, actualizada hasta el acto legislativo 1 de 2004.

Consta de 323 artículos ordinarios 2, y cinco disposiciones finales o transitorias del 324 al 328.

Título tercero. Derechos y deberes individuales y sociales.

Capítulo segundo, artículos 56-63, regulan el derecho a la familia: igualdad de derechos de los hijos, la creación de un organismo para la protección de la familia.

Capítulo tercero. El trabajo, artículos 64-79, regula el derecho al trabajo.

Capítulo cuarto. La cultura nacional, artículos 80-90, regulan el derecho a la cultura, el reconocimiento y respeto de la identidad étnica.

${ }^{86}$ http://www.asamblea.gob.ni/opciones/constituciones/ConstitucionPolitica.pdf. Fecha de consulta: 03 de febrero de 2012.

87 http://www.asamblea.gob.pa/main/LinkClick.aspx?fileticket $=f D g m R v Y W 8 c Y \% d \&$ tabid=123. Fecha de consulta: 3 de febrero de 2012. 
Capítulo quinto. Educación, artículos 91-108, regulan el derecho a la educación.

Capítulo sexto. Salud, seguridad social y asistencia social, artículos 109117, regulan el derecho a la salud, a la Seguridad social y asistencia social

Capítulo séptimo. Régimen ecológico, artículos 118-121, regulan el derecho al ambiente sano.

Capítulo octavo, artículos 122-128, los derechos agrarios y los derechos de las comunidades indígenas.

Artículos 129 y 130, establecen la acción de defensoría de los derechos.

\section{Paraguay $^{88}$}

Del 20 de junio de 1992.

Consta de 291 artículos ordinarios, 20 artículos finales y transitorios.

Título II. De los derechos, de los deberes y de las garantías, capítulo I con dos secciones, artículos 4 y 8 , regulan el derecho a la vida y al medio ambiente.

Capítulo cuarto. De los derechos de la familia, artículos 49-61, regulan el derecho a la familia, los derechos de la juventud y personas de la tercera edad (garantía a la salud y recreación).

Capítulo quinto. De los Pueblos indígenas, artículos 62-67, regulan Los derechos de los pueblos indígenas (preservación y desarrollo).

Capítulo sexto De la Salud

artículos 68-72, regulan El derecho a la salud.

Capítulo séptimo. De la educación y de la cultura. Se establece el mínimo presupuestario para la educación.

Artículos 73-85, derecho a la educación y a la cultura.

Capítulo octavo. Del trabajo. Con dos secciones: artículos 86-106, regulan el derecho al trabajo y el derecho a la seguridad social, tanto de la función pública como privada.

Capítulo IX. De los derechos económicos y de la reforma agraria. Sección II. De la reforma agraria, artículos 114-116, regulan derechos de la reforma agraria.

${ }^{88}$ http://www.diputados.gov.py/OD/constitucionnacional.pdf. Fecha de consulta: 2 de febrero de 2012. 
Perú $^{89}$

De 1993, consta de 206 artículos ordinarios, 16 disposiciones transitorias y 2 especiales.

Capítulo II. De los derechos sociales y económicos, artículos 4-29, regulan los derechos de los niños, adolescente, a la madre, los discapacitados y de los ancianos, el derecho a la familia; derecho a la salud; derecho a la seguridad social, a la educación y el derecho al trabajo.

Artículos 39-42, establecen los derechos laborales de los trabajadores de la función pública.

Capítulo VI. Del régimen agrario y de las comunidades campesinas y nativas, artículos 88 y 89 , regulan el derecho agrario, a través del reconocimiento de la personalidad de las comunidades agrarias.

\section{Uruguay $^{90}$}

De 1967, actualizada hasta el 31 de octubre de 2004.

Consta de 332 artículos ordinarios, 29 artículos transitorios y especiales.

Sección II. Derechos, deberes y garantías, capítulo I, artículos 32 y 36, regulan el derecho a la propiedad y al trabajo.

Capítulo II, artículos 40-42, 44, 46, 47, 53-57, 67-71, derecho a la familia, derecho a la salud, derechos de los indigentes: asilo o trabajo; derecho al medio ambiente sano, derecho al trabajo, derechos a la seguridad social y a la educación.

\section{Venezuela $^{91}$}

Del 30 de diciembre de 1999, actualizada al 2009.

Consta de 350 artículos ordinarios, 18 artículos transitorios, una disposición final y una derogatoria.

${ }^{89}$ http://www2.congreso.gob.pe/sicr/RelatAgenda/constitucion. nsf/\$\$ViewTemplate\%20for\%20constitucion?OpenForm. Fecha de consulta: 2 de febrero de 2012.

90 http://www0.parlamento.gub.uy/constituciones/const004.htm. Fecha de consulta: 2 de Febrero de 2012.

91 http://www.asambleanacional.gov.ve/index.php?option $=$ com_docman\&task $=$ cat_ view\&gid=250\&Itemid=184\&lang=es. Fecha de consulta: 2 de febrero de 2012. 
Capítulo V. De los derechos sociales y de las familias, artículos 75-97, derecho a la familia, los niños, adolescentes, jóvenes, ancianos, las personas con discapacidad; derecho a la propiedad; derecho a la salud, a una vivienda digna, derecho a la seguridad social; derecho al trabajo,

Capítulo VI. De los derechos culturales y educativos, artículos 98-111, derecho a la cultura, derecho a la educación, derecho a la ciencia y tecnología, derecho al deporte y a la recreación.

Capítulo VIII. De los derechos de los pueblos indígenas, artículos 119126 , regulan los derechos de los pueblos indígenas, como su reconocimiento de personalidad, a la salud, al medio ambiente, etcétera.

\section{$\operatorname{España~}^{92}$}

Del 27 de diciembre de 1978, modificada por reforma del 27 de agosto de 1992.

Consta de 169 artículos ordinarios, 9 artículos transitorios, 4 disposiciones adicionales.

Artículo 7o. establece el derechos de los sindicatos de trabajadores y asociaciones empresariales de velar por los intereses económicos y sociales propios.

Artículo 27 regula el derecho a la educación.

Artículos 28, 37 establecen derechos laborales, como la libertad sindical y el derecho de huelga, la negociación colectiva.

Artículo 35 derecho a la libertad de trabajo.

Artículo 43 el derecho a la salud.

Artículo 45 derecho a un medio ambiente adecuado.

Artículo 47 derecho a una vivienda digna.

Artículos 48 y 49 establece derechos de la juventud, de personas disminuidas, y de la tercera edad.

Artículo 51 derechos de los consumidores.

92 http://www.congreso.es/constitucion/ficheros/c78/cons_espa.pdf. Fecha de consulta: 2 de febrero de 2012 . 


\section{LA APLICACIÓN DE LAS POLÍTICAS ECONÓMICAS DE CORTE NEOLIBERAL EN MÉXICO}

En los últimos casi sesenta y cinco años se han registrado claramente dos grandes periodos de la economía mundial: el primero, que va de la segunda posguerra a 1973, tuvo un acelerado ritmo de crecimiento, reducido desempleo y estabilidad de los precios a lo largo de los años. La distribución del ingreso entre las personas y entre las clases que contribuyen a generarlo mejoró notablemente. En esos años, el pensamiento económico y las políticas instrumentadas por los gobiernos capitalistas occidentales estuvieron orientadas y dominadas por la influencia de las ideas de Keynes. Después de ese último año, el keynesianismo fue perdiendo fuerza y ganándola, imponiéndose, el pensamiento neoclásico-neoliberal. ${ }^{93}$

El neoliberalismo se puede definir desde varios puntos de vista. Es una ideología que legitima la competencia individual y cuestiona las estructuras colectivas. Es un proyecto político de transformación institucional, en contra de cualquier esfuerzo para establecer el "colectivismo" y también en contra de los diferentes tipos de capitalismo que han resultado de los diferentes compromisos socialdemócratas, en particular a partir de la segunda posguerra, tales como la protección social redistributiva, los derechos colectivos de los trabajadores o la protección legal del empleo y el estatus económico. También puede verse como una "forma de existencia", como una norma de vida caracterizada por la competencia generalizada entre todos... ${ }^{94}$

Ahora bien, en la era del neoliberalismo, el crecimiento de la economía mundial se redujo drásticamente, a pesar del espectacular desempeño de China, India y otros países asiáticos y latinoamericanos. El desempleo creció y se mantuvo a niveles relativamente altos y el ritmo de crecimiento de los precios, después de unos años, inició su descenso lento hasta finalmente estabilizarse. Creció la desigualdad en la distribución de la riqueza y del ingreso. La Revolución de los Ricos, antes de desembocar en la crisis económica que hoy se vive, transcurrió a lo largo de un período extenso. A nivel mundial arrojó fases prolongadas de acumulación y crecimiento,

93 Tello, Carlos y Jorge Ibarra, La revolución de los ricos, México, UNAM, 2012, p. 183.

${ }^{94}$ Amable, B., "Morals and politics in the ideology of neo-liberalism", Socio-Economic Review, 9, 2010, Oxford, p. 9. Citado por Tello, Carlos y Jorge Ibarra, op. cit., p. 22. 
que sin embargo no han sido uniformes entre los países. Algunos crecieron espectacularmente (China, India), otros a tasas previamente registradas en la historia del capitalismo pero inferiores a las de su Edad de Oro (Europa, Estados Unidos, Brasil). Algunos otros países en realidad han tenido un crecimiento modesto e insuficiente (como es el caso de México) y otros han retrocedido (como muchos de África). ${ }^{95}$

En México, las políticas de corte neoliberal datan de la época de Miguel de La Madrid, y se consolidaron con los sexenios venideros: Carlos Salinas de Gortari, Ernesto Zedillo Ponce de León, Vicente Fox y Felipe de Jesús Calderón Hinojosa.

La aplicación de las políticas económicas neoliberales, aparecen como el conjunto de recetas enfocadas a aplicarse en los países del tercer mundo que enfrentan serios problemas de endeudamiento externo con los países ricos, así como angustiante carencia de divisas para su desarrollo. En México, dicha problemática se presentó, a finales de los sexenios de Luis Echeverría Álvarez 1976, y de José López Portillo 1982.

A continuación, se menciona una síntesis de las políticas neoliberales que se aplican en todo lo ancho y largo de la República Mexicana, a partir de 1982 a 2012:

1. Reducción del gasto público.

2. Eliminación del déficit presupuestal, liquidado todo tipo de subsidios (incluyendo alimentos y transporte barato para los pobres).

3. Gran especulación del gran capital a través de un sistema financiero bajo su control (economía casino).

4. Reducción del tamaño del Estado, despido masivo de burócratas a quienes se considera altamente negativos y privatización de empresas paraestatales.

5. Mayor libertad económica para los empresarios, banqueros, industriales y comerciantes, lo que quiere decir que deben eliminarse todo tipo de controles a los empresarios. Es decir, la cada vez menor intervención del Estado en la economía.

6. El periodo de la total privatización, concentradora y monopolista.

7. De lo anterior se deriva que se eliminen los controles de precios, que no se limiten las ganancias, que no se grave al capital y que los salarios se fijen en función de las leyes de la oferta y la demanda.

95 Tello, Carlos y Ibarra, Jorge, op. cit., pp. 183 y 184. 
8. Desde el ángulo del sector externo, se recomienda la apertura total e indiscriminada a la inversión extranjera y a las mercancías provenientes del exterior. Para ello, se hace necesario un gobierno altamente sumiso a la inversión extranjera que les abra las puertas para que éstos hagan lo que quieran en el país, el cual prácticamente se les entrega. ${ }^{96}$

Esto implica leyes que permitan el libre movimiento de capitales y mercancías del exterior, a fin de atraer inversionistas extranjeros que se consideran los salvadores de la nación. En una palabra viene a ser una política desnacionalizante y subordinada a intereses del exterior.

9. La obsesión del Tratado de Libre Comercio.

10. Por lo anterior, viene a ser necesaria una política cambiaria altamente flexible que permita que entren y salgan libremente los capitales nacionales y extranjeros sin intervención por parte del Estado: es decir, la libertad para saquear a un país si en otro hay mayor seguridad o mayores tasas de ganancia. Por ello en los ajustes fondomonetaristas, lo primero que se exige al país endeudado es que elimine todo tipo de controles cambiarios.

11. Plena disciplina a la política exterior de los Estados Unidos.

12. Libre oportunidad de especular en bolsas de valores globalizadas mundialmente. ${ }^{97}$

Todo esto aceleró el desempleo abierto y disfrazado y fue el factor que generó uno de los más grandes cánceres del neoliberalismo que aparte de la delincuencia, se suma a otro problema llamado "ambulantaje", o "economía informal", o "subempleo". ${ }^{98}$

13. Atracción de inversiones extranjeras a como dé lugar.

14. Marcha atrás en las conquistas revolucionarias expresadas en la Constitución mexicana de 1917.

15. Reducción de la inflación.

16. Saneamiento de las finanzas públicas.

17. Control de los medios de difusión.

96 Cfr. Ortiz Wadgymar, Arturo, Política económica de México, 1982-1994, 2a. ed., México, Nuestro Tiempo, 1994, pp. 19 y 20.

97 Cfr. Ortíz Wadgymar, Arturo, op. cit., pp. 19 y 20.

98 Ibidem, p. 146 
También son importantes las concesiones a la iniciativa privada para que realice obras diversas de tipo turístico y de infraestructura, al igual que son paliativos las maquiladoras y los indocumentados. Pero cabe aclarar que por la recesión norteamericana estos dos últimos expedientes están en crisis, pues aparte de los bajos salarios en estos momentos el dólar del trabajador migratorio no vale mucho, debido a la congelación del tipo de cambio, lo que pagan las maquiladoras son sueldos de miseria. ${ }^{99}$

Baste recordar algunos datos para entender el cambio de actitud del gobierno mexicano respecto a la educación en la década de los noventa.

- La escolaridad promedio de la población económicamente activa (PEA) en Estados Unidos y Canadá es de 12 años en México, de 6 años.

- En México menos de $10 \%$ de la PEA cuenta con una carrera profesional.

- En Estados Unidos hay por cada 100 habitantes, 5.6 estudiantes de educación superior: en Canadá, 5.9 y en México, 1.5 .

- En México aproximadamente 7\% del financiamiento de la investigación proviene de la industria: en Estados Unidos, 50\% y en Canadá, 47 por ciento.

- Estados Unidos destina 2.6\% del PIB al gasto en investigación y desarrollo, Canadá $1.4 \%$, y México el 0.4 por ciento. ${ }^{100}$

En México existen más de 114 millones de habitantes, y su tasa de crecimiento es de $1.09 \%$, el ingreso per cápita es de 9,887 dólares anuales; para algunos, para otros, no rebasa los 3,700; oficialmente se reconoce que más de 53 millones de compatriotas viven en la pobreza y marginación, para ellos, no hay oportunidades de desarrollo: social, económico, educativo, salud y bienestar.

El desempleo impacta a la seguridad pública, en forma cotidiana, ya que existe un ambiente de incredulidad hacia nuestras instituciones y a la

99 Ibidem, p.156

100 Datos tomados de Javier Mendoza, La universidad frente a las tendencias de la globalización, Escenarios para la Universidad Contemporánea, UNAM, México, 1995, pp. 109-110, citado por Guevara González, Rosa Iris en Educación, sector productivo y neoliberalismo, Momento económico, información y análisis de la coyuntura económica, México, UNAM, Instituto de Investigaciones Económicas, enero-febrero de 1996, p. 30. 
legalidad. De ahí que se cuestione con mucha frecuencia a la procuración y administración de la Justicia.

Por su parte, Diego Valadés, considera que la pobreza, desarrollo y educación superior van de la mano. Empero, aceptar el fenómeno de la mundialización, internacionalización o tal vez incluso de la globalización, de una manera acrítica, puede ser un error de grandes y graves dimensiones. ${ }^{101}$

La era neoliberal en realidad no cumplió lo que pregonaba y ofrecía. El crecimiento económico en general fue inferior al de los años de la Edad de Oro del Capitalismo. En muchos países el desempleo fue relativamente mayor. En los países en los que el desempleo fue relativamente más bajo, esto se logró a costa del deterioro de los derechos laborales, el estancamiento en las remuneraciones, la precariedad de muchos empleos y la inseguridad laboral. El bienestar material para mucha gente en realidad empeoró o se sostuvo a través de un endeudamiento insostenible. La libre competencia, tan reverenciada, en realidad desembocó en la conformación de grupos de poder económico aún más fuertes y difíciles de batir en la esfera política. Además, el deterioro y la degradación ambiental creció y ahora el mundo se encuentra ante urgentes e impostergables disyuntivas: o se actúa para corregir el camino que se ha andado o se enfrentará una crisis sin precedente. ${ }^{102}$

Son justamente los países que están adoptando políticas neoliberales los que seguramente tendrán los peores resultados económicos en los años por venir. Y ello contrasta con los resultados de los países que se adapten en la crisis con políticas keynesianas. ${ }^{103}$

Lo inmediato en el terreno de la política es recuperar la idea de que el Estado de bienestar es la solución para la buena marcha de las economías del mundo. Que no tiene sentido proponer crecer para después distribuir. Que es necesario distribuir para crecer. Sólo así se fortalecerán las economías nacionales en el mundo de la globalización. Para que la globalización actúe en favor de las economías nacionales, es necesario nacionalizarla. ${ }^{104}$ Además, para México — se ha complicado — por el desbordamiento de la guerra contra el crimen organizado que ha costado más de 48 mil muertos oficialmente, otras fuentes mencionan más de 70 mil muertos.

101 Valadés, Diego, "Pobreza, desarrollo y educación superior”, Este País. Tendencias y opiniones, núm. 104, noviembre de 1999, p. 2.

102 Tello, Carlos y Jorge Ibarra, op. cit., pp. 187 y 188.

103 Idem.

104 Ortiz Wadgymar, Arturo, op. cit., p. 191. 
Así pues, para Salazar Ugarte: "La realidad mexicana nos arroja un cuadro desolador al término de la primera década del siglo XXI, cuando la Constitución cumple noventa y cuatro años, conviven millones de seres humanos en condiciones de pobreza con el hombre más rico del mundo". ${ }^{105}$

Por su parte, Patricia Kurczyn, considera: "Al retroceder noventa años, o un poco después, se puede advertir que ese constitucionalismo social que era como la base de hierro, indestructible y soporte para muchos más, empieza a perder vigencia". ${ }^{106}$

\section{INDICADORES SOCIOECONÓMICOS, EDUCATIVOS Y CULTURALES QUE ESQUEMATIZAN A LA REALIDAD LATINOAMERICANA}

América Latina tiene una población mayor a los 603 millones de personas. De los cuales, el $45 \%$ es pobre. Es decir, más de 250 millones de latinoamericanos tienen carencias económicas, sociales, etcétera. Empero, poco más de 50 millones se identifican como indígenas con altos índices de analfabetismo, y con ingresos miserables que apenas llegan a sobrevivir en la pobreza extrema.

Existen grandes diferencias en los niveles de pobreza entre los distintos países latinoamericanos (véase apartado IV). El de mayor porcentaje de pobres es Honduras, con $77 \%$, en el otro extremo está Uruguay con $15.4 \%$ de pobres. Con niveles de pobreza muy alta (con porcentajes del 60 al 70\% del total de la población) se encuentran Nicaragua, Bolivia, Paraguay y Guatemala; a estos países les siguen Perú, Colombia, El Salvador, Ecuador, Venezuela, República Dominicana y Argentina con niveles de pobreza alta (con porcentajes del 40 al $60 \%$ de la población); con grados medios de pobreza (entre el 30 y 40\% de la población) están: Brasil, México 50\% y Panamá; y finalmente Chile y Costa Rica con porcentajes bajos de pobreza (alrededor del $20 \%$ de su población). ${ }^{107}$

105 Salazar Ugarte, Pedro, "Pobreza", en Fix-Zamudio, Héctor y Valadés, Diego (coords.), op. cit., p. 300.

106 Kurczyn Villalobos, Patricia: Seguridad social; artículo publicado en: Fix-Zamudio, Héctor y Valadés, Diego (coords.), op. cit., p. 210.

107 Boltvinik, Julio y Damián, Araceu (coords.), La pobreza en México y el mundo. Realidades y desafios, México, Siglo XXI, 2004, p.135 
La concentración del apoyo en las áreas rurales se deriva de las visiones tan reducidas del problema de la pobreza de los organismos internacionales, sobre todo del Banco Mundial, reduciéndolo a uno de supervivencia, hambre y desnutrición, característico de las áreas rurales. Sin hacer a un lado la necesidad de resolver este problema, este reduccionismo de la pobreza ha dejado en el desamparo a un gran contingente urbano, que por mucho ha sido el más afectado por el desmantelamiento del estado de bienestar en la región y de los beneficios que emanaban de éste (véanse las contribuciones de Huber y Brachet en este mismo libro). ${ }^{108}$

A fin de lograr claridad sobre dicha problemática se recomienda consultar los siguientes cuadros comparativos con sus respectivas direcciones electrónicas:

1. UNFPA Estado de la población mundial 2011, Indicadores demográficos, sociales y económicos. Véase: http://foweb.unfpa.org/ SWP2011/reports/SP-SWOP2011_Final.pdf. Fecha de consulta: 1o. de febrero de 2012.

2. Porcentaje de la población que vive por debajo de usd $\$ 2$ al día. Véase: http://translate.google.com.mx/translate? $h l=e s \& s l=e n \& t$ $l=e s \& u=h t t p \% 3 A \% 2 F \% 2 F w w w . p r b . o r g \% 2 F$. Fecha de consulta: 1o. de febrero de 2012.

3. Porción de niños menores de 5 años con insuficiencia ponderal. Véase: http://websie.eclac.cl/sisgen/ConsultaIntegrada.asp?idA plicacion $=1 \&$ idTema $=4 \&$ idioma $=e$. Fecha de consulta: 1o. de febrero de 2012.

4. Datos demográficos y estimaciones sobre los países y regiones del mundo. Véase: http://translate.google.com.mx/translate? $h l=e s \&$ $s l=e n \& t l=e s \& u=h t t p \% 3 A \% 2 F \% 2 F w w w . p r b . o r g \% 2 F$. Fecha de consulta: 1o. de febrero de 2012.

5. Datos demográficos y estimaciones. Véase: http://translate.google. com. $m x /$ translate $h l=e s \& s l=e n \& t l=e s \& u=h t t p \% 3 A \% 2 F \% 2 F w w w$. prb.org\% $\%$. Fecha de consulta: 1o. de febrero de 2012.

6. Países por tasa de desempleo. Véase: http://es.wikipedia.org/wiki/ Anexo:Pa\%C3\%ADses_por_desempleo. Fecha de consulta: 1o. de febrero de 2012. 
7. Población indígena en México, http://www.inegi.org.mx/lib/ olap/consulta/general_ver4/MDXQueryDatos.asp?proy $=c p v 10$ p3mas. Fecha de consulta: 1o. de febrero de 2012, y http://www. inegi.org.mx/lib/olap/consulta/general_ver4/MDXQueryDatos. asp?\#Regreso \&c=27781. Fecha de consulta: 1 o. de febrero de 2012.

8. Tasa de analfabetismo de la población de 15 a 24 años, ambos sexos (porcentaje). Véase: CEPAL 2011. Anuario estadístico de América Latina y el Caribe, http://websie.eclac.cl/anuario_estadistico/ anuario_2011/esp/content_es.asp.

9. Estimación de la población indígena en América Latina. Véase: Atlas Sociolingüístico de Pueblos Indígenas en América Latina; Edición de UNICEF y FUNPROEIB Andes, 2009, http://www.proeibandes. org/atlas/tomo_1.pdf. Fecha de consulta: 3 de febrero de 2012.

10. Libertad económica y corrupción en América Latina 2012. Véase: Índice de Libertad Económica 2012; publicado por The Heritage Foundation Leadership for América, en colaboración con The Wall Street Jorunal, http://translate.google.com.mx/translate? $h l=e s \& s l=e n \& u=h t t p: / /$ www.heritage.org/index/default\&ei $=E M c 1 T 6 e 1 M-K C 2 A X T 15 j y A$ $Q \& s a=X \&$ oi $=$ translate $\& c t=$ result $\&$ resnum $=1 \& v e d=0 C C k Q 7 \mathrm{gEw}$ $A A \&$ prev $=/$ search $\% 3 F q \% 3 D w w w$.heritage.org/index $/ \% 26 h l \% 3 D$ es\%26biw\%3D1600\%26bih\%3D805\%26prmd\%3Dimvns. Fecha de consulta: 10 de febrero de 2012.

\section{REFLEXIONES FINALES}

Actualmente (2012), la población mundial oscila entre los siete mil millones de seres humanos, de este universo poblacional (para el 2050, seremos poco más de 10,000 mil millones personas ), se identifica a un porcentaje mayor al 50\% que vive en pobreza, es decir, aproximadamente más de cuatro mil millones de humanos son pobres. Dicha problemática, es cada vez más dramática por la explosión demográfica y se intensifica aun más por las asimetrías en la distribución del ingreso y de la riqueza. Dicha problemática se intensifica aun más por la aplicación de las políticas económicas neoliberales, ya que, para los simpatizantes del referido modelo económico, lo que importa es el crecimiento económico en beneficio de pequeñas elites, es decir, 225 personajes concentran más del $60 \%$ de la riqueza mundial. Algunos de ellos involucrados en corrupción, impunidad y 
mentiras, en cambio para los pobres hay menos oportunidades de desarrollo y con mayor frecuencia se acompañan de las enfermedades de la pobreza: desnutrición, tuberculosis, difteria, tifoidea, malaria, cólera, paludismo, sida, Ébola, etcétera. Además, de las desigualdades en el conocimiento científico y tecnológico. Otra problemática que se presenta es la falta de credibilidad en las instituciones jurídicas, sobre todo en lo concerniente a la administración, procuración e impartición de la justicia, situación que genera cuestionamientos a la legalidad y legitimidad en la gobernabilidad. Es por ello que la sociedad se cuestiona momento a momento ¿qué hacer? para lograr una convivencia humana menos inhumana.

Ahora bien, para comprender la complejidad que circunda a la pobreza como problemática fundamental - es imprescindible una perspectiva del conocimiento interdisciplinario y transdisciplinario, para el efecto de entender que la pobreza material se origina por múltiples causas: sociales, económicas, políticas, culturales, educativas, psicológicas, ideológicas, etcétera.

Durante muchos años ha permeado una visión errónea sobre la pobreza, ya que, de manera ingenua pero intencionada se ha dicho que la pobreza se origina en fallas del comportamiento del individuo, como la vagancia, el vicio, el alcoholismo. En distintos momentos de la historia se los ha considerado como delincuentes; en la Inglaterra victoriana ser pobre era equivalente a ser vago y merecía cárcel. Así pues, quienes piensan de esa manera, van a tener una actitud hacia los pobres y hacia la pobreza en general muy diferente de quienes piensan que ésta, se debe a fallas de los sistemas sociales. ${ }^{109}$

Por otra parte, no es casual que para conservar y fortalecer al sistema capitalista, se establezcan normas jurídicas protectoras de la seguridad social y de la justicia social. No obstante, en ocasiones, los simpatizantes de las ideologías conservadoras impregnadas en el liberalismo y en el neoliberalismo económico que actualmente se vive, lleguen éstos, a expresar que dichas políticas públicas están contaminadas de la ideología Marxista. Empero, desde una perspectiva crítica se puede considerar de acuerdo a James O'Connor, que:

los gastos sociales son en realidad formas transitorias, que se vuelven activas o no de acuerdo con los niveles del descontento popular antes que con, las

${ }^{109}$ Boltvinik, Julio, "Políticas focalizadas de combate a la pobreza en México. El progresa/oportunidades”, Boltvinik, Julio y Damián, Araceu, (coords.), op. cit., p. 315. 
necesidades sociales. Se trata, pues, de una actividad de control social por parte del Estado, y no de formas de legitimación del Estado y del mismo capitalismo, de democracia política. Por esta razón, el Estado se ve obligado a hacerse cargo permanentemente de los costes económicos y sociales de la acumulación, so pena de perder la capacidad de asegurarse el consenso político e ideológico. El capital social promueve la acumulación capitalista privada, lo cual, a su vez, requiere la extensión de los gastos sociales para prevenir o subsanar los costes sociales de la acumulación. ${ }^{110}$

Consecuentemente, cabe resaltar que, el constitucionalismo social en Latinoamérica surge y se desarrolla por las asimetrías que se reflejan en la distribución del ingreso y de la riqueza. A la Constitución Política de los Estados Unidos Mexicanos de 1917, le corresponde el derecho de ser la primer constitución del mundo que establece derechos sociales; la educación pública gratuita, proteger a la familia, brindarle asistencia de salud, seguridad social, impulsar la propiedad comunal y de carácter social, el patrimonio de familia, regular los derechos y deberes de los trabajadores, etcétera. Todos estos derechos sin duda alguna se establecen en beneficio de las grandes mayorías. De ahí que no es casual que la sociedad mexicana durante más de 60 años lograra una cierta estabilidad política y económica. Sin embargo, con la aplicación de las políticas económicas neoliberales en México aumenta la pobreza de manera vertiginosa, sobre todo a partir de la década de los 80s a la fecha. Ya que actualmente hablamos de más de 60 millones de mexicanos en pobreza, razones por las cuales, se recrudecen las desigualdades, y por ende, la paz social se resquebraja. Por lo consiguiente, no es casual el aumento del crimen organizado y de la existencia de más de 7 millones de jóvenes mexicanos que no tienen ni a corto, ni a mediano o largo plazo proyectos de oportunidades de desarrollo y que los identificamos como la generación de los ninis.

Ahora bien, con la aplicación de las políticas económicas neoliberales, actualmente, se transita del estado de bienestar al estado de malestar; los beneficios que se habían logrado años atrás con el establecimiento del constitucionalismo social, ahora se han frenado u obstaculizado, toda vez que, el Estado interventor ha dejado de participar en beneficio de la igualdad

${ }^{110}$ O'Connor, James, La crisis fiscal del Estado, 1a. ed. en español, Barcelona, Ediciones Península, trad. de Gerardo Di Masso y Josep M. Custodio (capítulos I, II y III), Ramón Coll (capítulos IV, V, VI, VII, VIII y IX), y Marco Aurelio Galmarini (apéndice), Barcelona 1981, pp. 321-323. 
para un mayor número de personas, ahora el Estado ha asumido un papel de guardián del crecimiento económico logrado por los menos, en perjuicio de la población depauperada. Razón por la cual, el Estado benefactor ha dejado de ser tal, ya que ahora, invierte e interviene más en la seguridad pública que en la seguridad social.

A la aplicación de las políticas económicas neoliberales se les identifica actualmente como la era de la revolución de los ricos, ya que, a través de la especulación y manipulación de los desequilibrios financieros del gran capital, han logrado hacer más pobres a los pobres y más ricos a pequeñas elites. La visión (neo) liberal es sólo una, desde la cual se puede observar los fenómenos de las políticas públicas, no la única. La tradición de la filosofía y teoría política liberal-elitista fue la que arrinconó el enfoque de las políticas públicas de los setentas y ochentas en, una postura donde sólo los especialistas podían decidir lo mejor para el resto de la sociedad, incluso llevó a algunos de ellos a asaltar el poder en nuestro país y reemplazar a la elite política tradicional. ${ }^{111}$

Los problemas relacionados con la reducción de la desigualdad mundial son verdaderamente intimidadores. No podemos dejar tales problemas a merced del errático torbellino de los mercados mundiales y de los relativamente impotentes cuerpos internacionales si queremos crear un mundo que combine estabilidad, equidad y prosperidad". ${ }^{112}$

La demanda social se hace presente mediante la opinión pública que se opone a la negación del otro, a la purificación étnica, a la guerra a muerte entre grupos étnicos, religiosos, políticos o sociales, al mantenimiento de las mujeres en una situación de inferioridad. Y esos movimientos sociales y culturales son hoy democráticos en su orientación principal, porque claman: vivamos juntos con nuestras diferencias. ${ }^{113}$

Los cultores del derecho están llamados a problematizar sobre la legalidad, funcionalidad y legitimidad de las instituciones jurídicas para su análisis, estudio de manera objetiva y racional, en mucho ayudará el enfoque interdisciplinario como perspectiva epistemológica para hacer a un lado, el exacerbado culto al positivismo jurídico que en aras de la pureza metódica

${ }^{111}$ Caldera Ortega, Alex Ricardo, "Políticas públicas y justicia social". Este país. Tendencias y Opiniones, México, núm. 167, febrero de 2005, p. 39.

${ }^{112}$ Cfr. Giddens, Anthony, La tercera vía. La renovación de la socialdemocracia, trad. de Pedro Cifuentes Huertas, Madrid, Taurus, 1999, p. 179.

${ }^{113}$ Giddens, Anthony, op. cit., p. 179. 
y de la neutralidad científica conservan y fortalecen el statu quo de las asimetrías tan insultantes que hoy día vivimos en toda la geografía del orbe.

Así pues, para Mauro Cappelletti, es significativo el compromiso que los juristas realicen con el acceso a la justicia tanto en el ocaso del segundo milenio como en la aurora del siglo XXI, a fin de hacerle frente al escalofriante panorama que se dibuja en las asimetrías que nos presentan las sociedades más pobres del planeta:

Como movimiento intelectual, el acceso a la justicia ha expresado una potente reacción contra la postura dogmático-formalista que pretendía identificar el fenómeno jurídico exclusivamente en las normas, olvidando así los otros elementos, no menos esenciales: sujetos, instituciones, procedimientos; sino que ha llevado también a una simplificación no menos irreal de las tareas y responsabilidades del jurista, juez, abogado, estudioso, tareas que, según dicha posición, deberían limitarse a un mero conocimiento y a la mera aplicación aséptica, pasiva y mecánica de las normas en la vida práctica, en la enseñanza y en el análisis científico. ${ }^{114}$

En esta postura formalista y degenerativa del positivismo jurídico, la interpretación de la norma no es otra cosa que "el resultado de un cálculo conceptual de estructura deductiva, fundado en una idea del ordenamiento como sistema de normas cerrado, completo y jerarquizado", con la doctrina del "silogismo judicial, para el cual la decisión es también el resultado objetivo de un cálculo deductivo"; mientras que el "instrumento considerado «seguro» de este cálculo es (precisamente) el método sistemáticodeductivo que tiene la ventaja doble - al menos así lo supone la doctrina en examen - de garantizar soluciones «ciertas» y «objetivas» y de excluir las elecciones subjetivas del juez". No menos importante es el hecho de que en esta postura formalista se acaba por identificar el derecho positivo con la justicia, o lo que es lo mismo, se rechaza la valoración del derecho positivo sobre la base de criterios de justicia, sociales, éticos, políticos, económicos. ${ }^{115}$ Es decir, es una concepción positivista decimonónica alejada de la realidad histórica concreta.

Consecuentemente, concibo a la justicia social como la expresión más humana, solidaria y racional para poder convivir con armonía con los demás. De ahí que sea necesario reforzar la cultura del respeto tanto al interés

114 Cappelletti, Mauro, Dimensiones de la justicia en el mundo contemporáneo, México, Porrúa, 1993, pp. 82 y 83.

115 Ibidem, p. 83. 
individual como al interés público en beneficio de la justicia social, a través de un ámbito más tolerante, abierto y plural que permita el desarrollo de un nuevo modelo de comunicación y de convivencia humana, que fortalezca el respeto a los derechos fundamentales del ser humano. Con el ánimo de evitar el holocausto, no podemos seguir sobreviviendo con la contaminación del agua, aire, fauna y flora. Así como de los alimentos que se obtienen a través de los transgénicos que a la larga producen enfermedades incurables, por ejemplo, el cáncer. Dicho drama ecológico en cierta forma obedece a los apetitos insaciables de quienes en forma egoísta sólo piensan y actúan para aumentar sus riquezas materiales a costa de la vida de los demás.

Será factible la generación de una conciencia solidaria que permita conservar y compartir a los que tienen todo con los que nada tienen. Mediante qué estrategias se podrá reducir la extrema pobreza que tanto degrada a la vida humana en todas sus expresiones.

¿Qué políticas tributarias permitirán una mayor distribución del ingreso y de la riqueza? ¿En qué forma los impuestos a la producción y el consumo facilitan la distribución del ingreso y de la riqueza o en su defecto hacen más pobres a los pobres? ¿Por qué razones no se grava a la riqueza ociosa en beneficio de la puesta en marcha de programas solidarios que permitan hacer la justicia social?

Esto significa que una persona privilegiada no puede evadir un conflicto personal continuo entre la búsqueda de la auto ventaja y las exigencias de la justicia social. Cualquiera que sea la forma en que resuelva mi conflicto privado entre autosatisfacción y justicia social, continuará siendo verdad que podría haber hecho más para servir a la justicia social, y que podría haber hecho más en favor de la auto-satisfacción. ${ }^{116}$

Por su parte, Anthony Giddens, al referirse a las desigualdades socioeconómicas existentes expresa lo siguiente:

Pequeñas élites, a veces objetivamente ricas, viven física y culturalmente aisladas de la gran mayoría. Con bastante frecuencia sacan sus ingresos abiertamente del blanqueo de dinero, el tráfico de armas o el de drogas. ${ }^{117}$

Los problemas relacionados con la reducción de la desigualdad mundial son verdaderamente intimidadores. No podemos dejar tales problemas a merced del errático torbellino de los mercados mundiales y de los relati-

116 Ackerman, Bruce, La justicia social en el Estado liberal, Madrid Centro de Estudios Constitucionales, Infortex, 1993, p. 418.

117 Giddens, Anthony, op. cit., p. 178. 
vamente impotentes cuerpos internacionales si queremos crear un mundo que combine estabilidad, equidad y prosperidad. ${ }^{118}$

Consecuentemente, estoy convencido al compartir con los cultores del Constitucionalismo Social de América Latina, que éste, se explica y justifica racionalmente como un antídoto para aminorar las asimetrías tanto en la distribución del ingreso como de la riqueza. Por medio de políticas públicas que fortalezcan el Estado de bienestar. ${ }^{119}$ Lamentablemente, los corifeos de las políticas económicas neoliberales por su miopía intelectual y apetito de ambición devoradora, egoístas, pragmáticos, utilitaristas y a ultranza individualistas, han obstaculizado el desarrollo del derecho social como paradigma racional y objetivo, para construir una sociedad más armónica, abierta, plural, tolerante y que permita promover oportunidades de desarrollo social para quienes se encuentran en pobreza. Al respecto, se fortalece la educación pública y gratuita, se impulsa la vivienda popular, la seguridad social, etcétera. Asimismo, se establecen las normas constitucionales que permiten una mayor planeación, participación e interacción

\section{Ibidem, p. 179.}

119 A este respecto, Esping-Andersen, clasifica los modelos del Estado de bienestar en tres tipos:

El modelo dominado por la asistencia social, al que llama modelo "liberal" o residual, donde los derechos a la asistencia dependen de la demostración de necesidad. Es decir, tiene que comprobar que no tiene medios suficientes y que, por tanto, necesita la asistencia social, al igual que en las leyes de pobres del siglo XIX.

El segundo modelo es el de seguridad social obligatoria o "conservador corporativista “, que provee derechos amplios a los asegurados, pero los beneficios dependen casi totalmente de las contribuciones individuales.

En el tercer modelo, "socialdemócrata", los principios de universalismo y desmercantilización fueron extendidos también a las nuevas clases medias. Dice Esping-Andersen, lo evitaron los países que adoptaron el modelo socialdemócrata elevando la calidad de las prestaciones que el estado proporciona y, por tanto, incorporando plenamente a toda la población. Otro elemento de este modelo es que los costos de la reproducción familiar son socializados, estimulando la independencia individual al otorgar transferencias directas a los menores y a los ancianos e inválidos. Es decir, a diferencia del modelo conservador que lo hace todo a través de la familia y, por tanto, mantiene la dependencia de los jóvenes respecto de sus padres, en el modelo socialdemócrata las transferencias son directas, con lo cual éste se libera de ese autoritarismo familiar que tanto hombres y mujeres jóvenes sufren. Pero el elemento distintivo es que este modelo está comprometido con la garantía del pleno empleo; de tal manera que el derecho al trabajo queda en condiciones de igualdad con el derecho a la protección plena del ingreso. Boltvinik, Julio, "Políticas focalizadas de combate a la pobreza en México. El progresa/oportunidades", op. cit., pp. 316 y 317. 
del Estado, para el efecto, de hacer menos desiguales a los desiguales. A fin de construir una cultura democrática, como lo concibe el artículo 30. en su fracción II inciso a de nuestra Constitución Política de los Estados Unidos Mexicanos de 1917, en donde, expresa: "a la democracia no solamente como una estructura jurídica y un régimen político, sino como un sistema de vida fundado en el constante mejoramiento económico, social y cultural del pueblo". Al respecto, Alain Turain, considera: "la función de la democracia es la de asegurar el control social de la actividad económica e impedir que un sistema de medios se transforme en sistema de fines. El espíritu democrático impone la primacía de la política sobre la economía". ${ }^{120}$

Por otra parte, cabe resaltar, que en México los buenos propósitos para erradicar la pobreza no han faltado. Al respecto, cabe citar: el programa Oportunidades (Progresa/Oportunidades) considera, que la pobreza está determinada por la interacción perversa entre bajos niveles educativos y bajos ingresos. ${ }^{121}$ Es decir, a mayor nivel educativo mayores ingresos y mejores oportunidades de tener empleo y, contrariamente, a menor nivel educativo menores ingreso, y por lo consiguiente, menores oportunidades de tener empleo.

Sin embargo, el Progresa pone en duda el elemento central del diseño de Oportunidades, que apuesta todo a que el aumento en el nivel educativo de las nuevas generaciones los hará salir de la pobreza cuando sean adultos. La evidencia analizada señala que en los últimos 30 años personas con mejor educación tienen ingresos cada vez más bajos. ${ }^{122}$

Además, cabe resaltar, la publicación de la Ley General de Desarrollo Social aprobada en diciembre de 2003 y promulgada en enero de 2004 prevé la creación del Consejo Nacional de Evaluación de la Política de Desarrollo Social, tanto para que se haga cargo de las evaluaciones de los programas sociales como para que defina el método de medición de la pobreza y lleve a cabo mediciones periódicas. ${ }^{123}$ Además, la eficacia de dicha ley es muy endeble, toda vez que se han restringido los recursos económicos para el desarrollo social en nuestro país.

120 Turaine, Alain, ¿Podremos vivir juntos?, 2a. ed.México, Fondo de Cultura económica, 1997, p. 264.

121 Poder Ejecutivo Federal, Programa de Educación, Salud y Alimentación. Aunque el documento carece de fecha y de pie de imprenta, fue impreso en 1997, año de arranque del programa. Citado por Turaine, Alain, op. cit., p. 343.

122 Idem.

123 Boltvinik, Julio, "Políticas focalizadas de combate a la pobreza en México. El progresa/oportunidades", op. cit., pp. 346 y 347. 
Sin embargo, en México recientemente se ha instrumentado una política crediticia de 2 mil 500 millones de pesos para fortalecer la privatización de la educación superior. ${ }^{124}$ En lugar de fortalecer los subsidios para beneficios de las universidades públicas de nuestro país, que son los centros genuinos de la generación del conocimiento mediante la investigación científica, tecnológica y humanística.

México sigue siendo un país indecente. Lo es porque más de 19 millones de personas viven en condiciones de pobreza alimentaria; más de 26 millones en situación de pobreza de capacidades (que los incapacita para vivir la vida a la que aspiran); más 50 millones son víctimas de pobreza patrimonial (no cuentan con los recursos necesarios para cubrir sus gastos de alimentación, educación, vestido, salud, vivienda y transporte). ${ }^{125}$ Esa situación, en sí misma, sin necesidad de contrastarla con las cifras que evidencian la otra cara ominosa de la indecencia mexicana -la desigualdad-, impide calificar a nuestro país como una nación moderna. Para llegar a esa conclusión, de hecho, basta con utilizar como parámetro las coordenadas ideales del modelo democrático constitucional que hemos decidido adoptar y que, como ya he advertido, están contenidas en nuestra Constitución desde 1917. Para decirlo sin rodemos (sic - rodeos-): nuestro documento constitucional promete un proyecto social que no corresponde con nuestra realidad cotidiana. Esta situación ominosa, por un lado, demuestra la ineficacia del documento $\mathrm{y}$, por el otro, anuncia la posible erosión del pacto de conveniencia que el mismo expresa. ${ }^{126}$

Por otra parte, cabe resaltar, que México hace más de dos años celebró el bicentenario de su independencia (1810-2010) y el centenario de su revolución (1910-2010), pero dichas celebraciones se enmarcan en el contexto de una grave crisis económica, política, social y de valores, por lo tanto, los escenarios de inconformidad se acrecientan cada día con motivo de la crisis financiera que ha sido cobijada en el esquema del neoliberalismo globalizado. Además, cabe resaltar, que con motivo de la inseguridad pú-

124 Cfr. Ramos, Jorge, Calderón anuncia 23 mil créditos estudiantiles; artículo publicado en el Periódico El Universal, Sección Nación, de 9 de enero de 2012, p. 36.

125 Tomo los datos del documento Equidad Social y Parlamentarismo publicado por el Instituto de Estudios para la Transición Democrática en 2010, http://ss1.webkreator.com. $m x / 4 \_2 / 000 / 000 / 053 / f 49 / E q u i d a d-s o c i a l-y$-parlamentarismo.pdf. Citado por Salazar Ugarte, Pedro, op. cit., p. 300.

126 Salazar Ugarte, Pedro, op. cit., pp. 300 y 301. 
blica generada por el narco terror y su combate mediante la guerra contra el crimen organizado ha sumado más de 48,000 cuarenta y ocho mil muertos según la versión oficial, otras fuentes mencionan más de 70 mil muertos (2006-2012).

Así pues, para Pedro Salazar Ugarte, la pobreza es una calamidad y no una catástrofe: "Es una calamidad porque detrás de la misma —al menos en el contexto mundial y nacional actual en el que existen potencialmente los medios y los recursos necesarios para erradicarla-, como causa parcial de su persistencia, se encuentran acciones u omisiones humanas intencionales. Por ello y sólo por ello tiene sentido emitir juicios de valor en torno a la misma y calificar como "injustas" o "indecentes" a las situaciones y contextos en los que la misma prevalece. Si, por el contrario, la pobreza es una catástrofe; ${ }^{127}$ es decir, una "desgracia, desastre o miseria provocado por causas naturales que escapan al control humano"; ${ }^{128}$ no tendría sentido reflexionar sobre la misma en términos de (in)justicia. Se trataría de un hecho insuperable producto de la mala suerte o de la fatalidad ante el que sólo cabría la resignación y, en todo caso, la compasión. De la misma manera que resulta absurdo cuestionar la injusticia de un terremoto, si la pobreza fuera una catástrofe, sería necio enjuiciarla moralmente".

A este respecto, es preocupante la consideración expresada por José Francisco Paoli Bolio, quien menciona lo siguiente:

"Lo grave, advierte Paoli, es que México, hundido en una crisis económica, avanza hacia un estallido social: El problema no va a ser guerrillero. Los estallidos sociales son terribles cuando los provoca el hambre". ${ }^{129}$

Las autoridades gubernamentales argumentaron que la devastadora crisis económica de 2008 tuvo efectos menos sensibles en México que en los Estados Unidos y en general que en otras partes del mundo. Empero, en materia de salarios la Organización Internacional del Trabajo consideró que a partir de ese año México, Islandia e Irlanda

127 Sobre la diferencia véase Garzón Valdés, E., Calamidades, Barcelona, Gedisa, 2004. Citado por Salazar Ugarte, Pedro, op. cit., p. 302

128 Ibidem, p. 12. Citado por Salazar Ugarte, Pedro, op. cit., p. 302

129 Delgado, Álvaro (entrevistador), Paoli, Francisco José (entrevistado), "Partido pragmático, gobierno sin iniciativa", Proceso, Semanario de información y análisis, México, núm. 1713, 30 de agosto de 2009. p. 19. 
presentaron "una participación de los salarios extremadamente volátil”. ${ }^{130}$ En Islandia e Irlanda ese sacrificio de los trabajadores acompañó una drástica caída de la economía; en México la volatilidad salarial obedeció a otros factores. En 2009 todos los países latinoamericanos registraron un aumento en el salario mínimo mensual real, con excepción de México, Panamá, Perú y Venezuela. ${ }^{131}$

Lamentablemente, para los sectores populares y marginados de México, se avizora una Reforma Laboral que trastoca los derechos sociales. A este respecto, el jurista y constitucionalista mexicano Diego Valadés, considera:

En lo concernido con el trabajo, Keynes señalaba la importancia de la certidumbre y la previsibilidad de los precios y de los salarios. Como observa Skidelsky, ${ }^{132}$ la tendencia a flexibilizar los contratos de trabajo implica un factor de incertidumbre que genera injustica en las relaciones sociales, además de efectos nocivos para la economía. Cuando se pretende involucrar a los partidos políticos en la asunción de medidas legislativas orientadas al trabajo precario lo que en realidad se desea es poner a disposición del aparato productivo trabajo eventual barato, sin importar los efectos negativos que esa situación tenga en los trabajadores y en sus familias. El argumento de que lo mejor para los trabajadores es no saber cuándo y cuánto trabajarán es una falacia muy extendida.

Un importante estudio de Joseph Stiglitz, Amartya Sen y Jean-Paul Fitoussi ${ }^{133}$ demuestra que la sola medición del producto nacional bruto no ofrece indicios suficientes para evaluar la calidad de la vida de las personas y de las comunidades nacionales. ${ }^{134}$ En especial observan que la inseguridad laboral que resulta del trabajo precario tiene consecuencias adversas para la salud física y mental de los trabajadores y de sus familia-

130 Informe mundial sobre salarios 2010/2011, p. 26. Citado por Valadés, Diego, "Responsabilidad social del Estado constitucional", Fix-Zamudio, Héctor y Valadés, Diego (coords.), op. cit., p. 378.

131 Ibidem, p. 125. Citado por Valadés, Diego, op. cit., p. 378.

132 Skidelsky, op. cit., p. 148. Citado Valadés, Diego, op. cit., p. 381.

133 Stiglitz, Joseph et al., Mismeasuring our lives, Nueva York, New Press, 2010, pp. 84 y ss. Citado por Valadés, Diego, op. cit., p. 381.

134 En este mismo sentido véase Kahneman, Daniel, y Deaton, Angus, "High income improves evaluation of life but not emotional well-being", en Proceedings of the National Academy of Sciences, septiembre 21, 2010. Puede verse en http://www.princeton.edu/-deaton/ downloads/deaton_kahneman_high_income_improves_evaluation_August2010.pdf. Citado por Valadés, Diego, op. cit., p. 381. 
res, y afecta asimismo a las corporaciones por la falta de motivación para los trabajadores, por la disminución de la productividad y por la pérdida de identidad de los empleados con la empresa. Puede agregarse que este tipo de relaciones de trabajo perjudica en su conjunto a la sociedad porque genera nuevas formas de estratificación.

Es importante remediar los desvíos a los que se ha llegado en perjuicio de los intereses y de los derechos sociales y también evitar una recaída en el autoritarismo burocrático. La responsabilidad pública consiste en remediar las deformaciones institucionales que están en el origen de la pobreza, de la violencia, de la arbitrariedad y de la corrupción.

La construcción de instituciones sociales y políticas que garanticen equidad implica un nuevo tipo de equilibrios que son posibles si se utilizan, en el gran escenario del poder, los nuevos instrumentos del saber. ${ }^{135}$

Por último, sólo me resta expresar lo siguiente.

"La pobreza degrada y destruye, moral, social y biológicamente, el más grande milagro cósmico: la vida humana. La existencia de la pobreza es una aberración social". ${ }^{136}$ Sobre todo cuando es producto de la perversa manipulación de unos cuantos en contra de los más pobres.

135 Valadés, Diego, op. cit., p. 388.

136 Boltvinik, Julio y Damián, Araceu, "Introducción. La necesidad de ampliar la mirada para enfrentar la pobreza", ibidem, p. 11.

Fecha de recepción: 15 de febrero de 2012.

Fecha de dictamen: 20 de mayo de 2012. 
DR @ 2012, Universidad Nacional Autónoma de México, Instituto de Investigaciones Jurídicas 